\title{
IX. Vom Justizbeschluß der SED zum Neuen Kurs (1951-1953)
}

\section{Der SED-Justizbeschluß vom Dezember 1951: Vorgeschichte und Folgen}

Nach der Kampagne zur „Demokratisierung“ des Justizwesens im Jahre 1948 befaßten sich die Führungsgremien der SED immer wieder mit Justizfragen, jedoch lange Zeit nicht mehr in einem derartig grundsätzlichen Sinne wie 1948. Eine ähnlich weitreichende Bedeutung kam erst wieder dem Politbürobeschluß vom 11. Dezember 1951 über „Maßnahmen zur Verbesserung der Arbeit der Justiz“ zu. Während der Beschluß aufgrund einer parteiamtlichen Veröffentlichung seit 1952 bekannt ist ${ }^{1}$ und DDR-Forscher wie juristische Zeithistoriker nach 1990 in seiner Bewertung im wesentlichen übereinstimmen ${ }^{2}$, liegt seine Vorgeschichte und der Prozeß der Entscheidungsfindung noch weitgehend im Dunkeln.

Eine wesentliche Voraussetzung für die SED-Führung, sich mit dem Justizwesen eingehend zu befassen, bildete die massive Justizkritik in einer Aufzeichnung der ZKK, die Lange am 27. Juni 1951 Ulbricht übermittelte. Der Erfahrungsbericht beruhte auf Fällen, „wie sie sich aus der Zusammenarbeit zwischen den Organen der Staatlichen Kontrolle und den Organen der Justiz zwangsläufig ergeben haben". Die Beanstandungen der ZKK bezogen sich weitgehend auf das Justizpersonal und dessen Schulung: Die älteren Justizjuristen würden nicht in ausreichendem Maße umerzogen, bei der Auswahl der Volksrichter würden nach wie vor Fehler gemacht, und die Absolventen der ersten Lehrgänge erhielten zu wenig Anleitung, so daß insgesamt "der in Objektivismus machende Richter" weitaus zahlreicher vorhanden sei als generell angenommen. Die ZKK stellte zusammenfassend fest: „Die Justiz hat sich um die Pflege ihrer Kaderarbeit bisher so gut wie nicht gekümmert." Aber auch auf ihren anderen Arbeitsgebieten - etwa im Untersuchungsverfahren, in der Rechtsprechung und im Strafvollzug - habe die Justiz „dem Schutz und der Förderung unserer DDR schlecht gedient". Belegt wurden diese Vorwürfe mit zahlreichen Beispielen, die die angeblich „reaktionäre“ Einstellung der Richter und Staatsanwälte belegten. Gegen den Strich gelesen, wies der ZKK-Bericht folglich darauf hin, daß das Justizpersonal noch keineswegs völlig gleichgeschaltet war, auch wenn nicht jede kritische Äußerung über Richter oder Staatsanwälte als Aufbegehren oder gar Widerstand dieser Juristen gegen mangelnde Rechtsstaatlichkeit verstanden werden darf. Ebenso eindeutig wie das

2 Vgl. Benjamin u. a., Geschichte der Rechtspflege 1949-1961, S. 111 f.; Rottleuthner, Zur Steuerung der Justiz, S. 22-25; Teildruck des Beschlusses in: Dreier u. a., Rechtswissenschaft, S. 49-56. 
Urteil war die Stoßrichtung des ZKK-Berichts: „Überall, wo die Zentrale Kommission für Staatliche Kontrolle in ihrer Arbeit auf Schwächen oder Versagen der Justiz gestoßen ist, war letzte Ursache die mangelnde Kontrolle und feblende Anleitung des Ministeriums [der Justiz].“ Da das MdJ bei seiner „Kaderarbeit“ und bei der direkten Justizsteuerung aus Sicht der ZKK versagt hatte, forderte der Bericht abschließend die SED auf, „ihren Blick entschiedener als bisher der Justiz $\mathrm{zu}[\mathrm{zu}]$ wenden, um auch hier ihre fübrende Rolle verwirklichen zu können“. Es folgten weitere Vorschläge zur Verbesserung der Kaderarbeit, zur Beseitigung der „formaljuristischen Praxis“ im Verhältnis zwischen Richtern und Staatsanwälten, zur Überprüfung aller Amtsgerichte auf ihre gesellschaftliche Struktur, zur Änderung der Arbeitsweise der MdJ-Kontrollabteilung sowie zu einer gründlichen personalpolitischen Überprüfung des $\mathrm{MdJ}$, der Landesjustizverwaltungen, des Obersten Gerichts und der Obersten Staatsanwaltschaft sowie der Lehrkräfte an den Richterschulen und Universitäten ${ }^{3}$.

Vor dem Hintergrund von Langes Bericht sah Ulbricht offensichtlich die Notwendigkeit, die Partei zu aktivieren. Die Abteilung Staatliche Verwaltung erhielt den Auftrag, die Halbjahresberichte des MdJ, des Obersten Gerichts und der Obersten Staatsanwaltschaft im Lichte der ZKK-Kritik zu überprüfen 4 . Das Ergebnis wurde in einem Memorandum mit dem Titel „Über die Verbesserung der Arbeit in der Justiz" festgehalten. Das Schriftstück vom August oder September 1951 bezog sich ausdrücklich auf den Bericht Langes und übernahm zahlreiche Kritikpunkte einschließlich der dort genannten Beispiele; aus den Halbjahresberichten des DDR-Generalstaatsanwalts und des MdJ wurde lediglich das angeführt, was die von der ZKK erhobenen Vorwürfe nochmals untermauerte. Sogar die verhaltene Kritik an der SED-Justizarbeit, die „ungenügend“ gewesen sei oder „zum Teil ganz gefehlt" habe, wurde darin aufgegriffen'. Sehr viel heftiger fiel die Kritik am Justizministerium aus. Fechner hatte am 14. August 1951 den Halbjahresbericht über die Tätigkeit der Staatsanwaltschaften und Gerichte an Grotewohl übersandt und vorgeschlagen, diesen bei einer Regierungssitzung zu besprechen. Er sah darin eine treffliche Gelegenheit, die Justiz - und sich - im besten Lichte zu präsentieren, denn die Darlegungen des MdJ zeugten seiner Meinung nach „von einer stetigen Aufwärtsentwicklung auf fast allen Gebieten der richterlichen Tätigkeit" 6 . Die Erwartungen Fechners wurden jedoch bitter enttäuscht. Seine Ausführungen wurden nach dem dürren Protokoll am 23. August vom Ministerrat lediglich „zur Kenntnis genommen“; daß die Arbeit der Justiz dabei ziemlich heftig kritisiert worden sein muß, geht aus dem Auftrag an den Justizminister hervor, „dem Ministerrat Vorschläge über die sachliche und persönliche Qualifizierung der Arbeit in der Justiz zu unterbreiten"7. Aller Wahrscheinlichkeit nach waren dies erste Auswirkungen des ZKK-Berichts.

3 ZKK-Bericht über die Verhältnisse in der Justiz der DDR, mit Begleitschreiben von Lange an Ulbricht, 27. 6. 1951, BAB, DC1 Nr. 5248. Hervorhebungen im Original.

4 Vgl. Protokoll der Politbürositzung, 13. 11. 1951, Anlage: „Betrifft: Maßnahmen zur Verbesserung der Arbeit in der Justiz“, SAPMO, DY 30 J IV 2/2/176, Bl. 7.

5 Anlage a) Memorandum: Über die Verbesserung der Arbeit in der Justiz, ebenda, Bl. 8-15.

6 Fechner an Grotewohl, 14. 8. 1951, BAB, DP1 VA Nr. 5806.

7 Protokoll der Regierungssitzung, 23. 8. 1951, BAB, DC 20 I/3 Nr. 65, TOP 1, Bl. 120. 
Das Justizministerium lehnte sich bei der Ausarbeitung seiner Vorschläge eng an das von der Abteilung Staatliche Verwaltung erarbeitete Memorandum einschließlich eines daran angehängten umfangreichen Forderungskatalogs an und zeigte damit, daß es sich dem Führungsanspruch der SED im Justizwesen bedingungslos unterordnete ${ }^{8}$. Das dreigeteilte Papier des MdJ befaßte sich an erster Stelle mit Schulungsfragen: Es ging dabei vor allem darum, die Fortbildung der Justizjuristen zu reorganisieren, um die Reakademisierung der Juristenausbildung unter sowjetischen Vorzeichen (dazu sollte ein rechtswissenschaftliches Institut zur Entwicklung von wissenschaftlichem Nachwuchs gebildet werden), die Begründung einer theoretischen Zeitschrift sowie die Übernahme und Verbreitung von Material aus der sowjetischen Rechtswissenschaft. Zweitens wurde die Personalpolitik thematisiert, die beim MdJ bzw. DDR-Generalstaatsanwalt zu vereinheitlichen war; gleichzeitig stand eine striktere personelle Kontrolle des juristischen Nachwuchses vor Ausbildungsbeginn an der juristischen Fakultät oder der Zentralen Richterschule durch Auswahlkommissionen auf dem Programm. Unter der Überschrift „sachliche Qualifizierung" wurde drittens eine ganze Reihe von Maßnahmen zur Steuerung der Tätigkeit der Gerichte und der Rechtsprechung ins Auge gefaßt; nur in diesem Punkt hatte das MdJ die SED-Vorschläge um einige eigene ergänzt ${ }^{9}$.

Parallel zum MdJ arbeitete auch die Abteilung Staatliche Verwaltung eine Vorlage mit dem Titel: „Verbesserung der Arbeit in der Justiz“ aus, die zahlreiche Überschneidungen mit den MdJ-Vorschlägen aufwies. Nicht im MdJ-Papier enthalten waren die Abschnitte zur Verbesserung der Parteiarbeit in der Justiz sowie ein unmittelbar auf den ZKK-Bericht zurückgehender Passus zur "Säuberung“ des Justizpersonals: Demzufolge waren für den Justizdienst „untragbar[e]“ Richter und Staatsanwälte nicht nur in weniger verantwortliche Positionen zu versetzen, sondern fristlos zu entlassen; außerdem durften Richter, die eine Betätigung in Strafsachen ablehnten, "künftig nicht mehr in Zivilsenate versetzt werden, sondern [waren] unter dringlichem Hinweis auf ihre politische Verantwortung dort zu belassen oder überhaupt aus der Justiz zu entfernen "10. Das Sekretariat des ZK stimmte am 8. Oktober nicht nur der SED-Vorlage, sondern auch den Vorschlägen des MdJ zu: Die Angelegenheit wurde offensichtlich als zu wichtig erachtet, als daß sie der Regierung ohne vorherige Absegnung durch ein Führungsgremium der Partei unterbreitet werden konnte. Besondere Aufmerksamkeit wurde dem zu errichtenden rechtswissenschaftlichen Institut zuteil: Das Sekretariat beauftragte die Abteilung Staatliche Verwaltung und das MdJ, eine umfassende Vorlage dazu zu unterbreiten, und ordnete an, daß dessen Leiter „ein gut geschulter MarxistLeninist" sein müsse. Zusätzlich beschloß es, die Studenten der juristischen Fakultäten durch eine Kommission des $\mathrm{MdJ}$ überprüfen zu lassen, und wies die $\mathrm{Ab}$ teilung Staatliche Verwaltung an, „eine Direktive für die Landes- und Kreisleitun-

8 Siehe Memorandum über die Verbesserung der Arbeit in der Justiz, o.D., BAB, DP1 VA Nr. 263. Es handelt sich dabei um eine Vorlage zu der gleichnamigen Anlage zur Politbürositzung vom 13. 11.1951 (vgl. Anm. 5).

9 Vorschläge des MdJ über die sachliche und persönliche Qualifizierung der Arbeit der Justiz entsprechend dem Beschluß der Regierung der DDR auf ihrer Sitzung am 23.8. 1951, in: SAPMO, DY 30 J IV 2/3/239, Anlage Nr. 4a zum Protokoll der Sekretariatssitzung vom 8. 10. 1951.

10 Anlage Nr. 4 zum Protokoll der Sekretariatssitzung vom 8. 10. 1951, ebenda. 
gen über die Arbeit der Parteiorganisation im Justizapparat auszuarbeiten"11. Die MdJ-Vorschläge konnten am 25. Oktober der DDR-Regierung vorgelegt werden, die diese, wie nicht anders zu erwarten, widerspruchslos zur Kenntnis nahm ${ }^{12}$. Zwei Tage danach veranstaltete das MdJ eine groß angelegte Arbeitstagung mit den Leitern der Hauptabteilungen Justiz der Länder, den Oberlandesgerichtspräsidenten und den Landgerichtspräsidenten, um eine möglichst rasche Umsetzung des Beschlossenen zu gewährleisten ${ }^{13}$.

Der ZKK-Bericht hatte sowohl den Partei- als auch den Justizapparat im Sinne einer effektiveren Indienstnahme der Justiz durch die SED aktiviert. Mit der Durchführung der vom Sekretariat am 8. Oktober 1951 beschlossenen Maßnahmen wäre die Angelegenheit wohl auch vorerst beendet worden, wenn nicht in den ersten Novembertagen die SKK mit einem auch justizrelevanten Forderungskatalog an die DDR-Führung herangetreten wäre. Die Anweisung kam in Form eines undatierten, unadressierten „Memorandums“, das, wie sonst auch, vom SKK-Chef direkt an den DDR-Ministerpräsidenten übermittelt wurde ${ }^{14}$. Sie bestand zum großen Teil aus Beanstandungen an den DDR-Repressionsapparaten, denen nicht so sehr mangelnde Effizienz, sondern im Gegenteil zu weitgehende Willkür und Härte vorgeworfen wurde. Die SKK wies daher an, Verhaftungen „in strenger Übereinstimmung mit den in der DDR gültigen Gesetzen" vorzunehmen, die Angehörigen über verhängte Urteile zu benachrichtigen, genaue Termine für das Untersuchungs- und das Gerichtsverfahren festzuschreiben, das Jugendstrafrecht $\mathrm{zu}$ reformieren, die Untersuchungsorgane zu überprüfen sowie von „reaktionären und zweifelhaften Elementen" zu reinigen und Auswahl, Schulung und Fortbildung des Personals von Staatssicherheit, Polizei und Justiz zu verbessern. Personal und Arbeit der für politische Sachen zuständigen Strafkammern sollten überprüft, die Reste beseitigt und die Rechtsprechung verbessert werden. Waren diese Anweisungen, wie das Memorandum selbst nahelegte ${ }^{15}$, vor allem dazu gedacht, aus deutschlandpolitischen Gründen die Vorbehalte im Westen gegen die repressive Dimension der DDR-Innenpolitik abzubauen, um die Chancen für eine Wiedervereinigung zu erhöhen, schimmerte bei zwei anderen Anordnungen eine mehr oder weniger deutliche Sowjetisierungsabsicht durch. Denn die Aufsicht über die gerichtliche Untersuchung und die Hafträume war, wie in der Sowjetunion, der Staatsanwaltschaft zu übertragen, und die „Bearbeitung“ des Gerichtverfassungsgesetzes, der „Verordnung über die Staatsanwaltschaft“, der Strafprozeßordnung und des Strafgesetzbuches sollten „in nächster Zeit“ beendet werden. Letztere Anweisung lief darauf hinaus, von den noch in beiden deutschen

11 Protokoll der Sekretariatssitzung vom 8. 10. 1951, ebenda.

12 Protokoll der Regierungssitzung, 25. 10. 1951, BAB, DC 20 I/3 Nr. 74, TOP 7, Bl. 3. Rottleuthner, Zur Steuerung der Justiz, S. 22, datiert den Beschluß des Ministerrats irrtümlich auf den 23. 8. 1951 und geht nicht weiter auf ihn ein.

13 Protokoll der Arbeitstagung, 27. 10. 1951, BAB, DP1 VA Nr. 265, Bl. 80-86; vgl. auch die Zusammenfasssung der Tagungsergebnisse, ebenda, Bl. 64-66. Fechners Referat auf dieser Arbeitstagung in: BAB, DP1 VA Nr. 6999.

14 Die russische Anweisung in: SAPMO, NY 4090/301, Bl.75f.; auf der deutschen Übersetzung (Bl. 73 f.) der handschriftliche Vermerk „Nov. 51“.

is Vgl. dazu folgenden Satz des Memorandums: „Die Mängel und Fehler rufen in der Bevölkerung eine gewisse Unzufriedenheit hervor und werden außerdem von der in- und ausländischen Reaktion im Kampf gegen die demokratischen Kräfte ausgenutzt." 
Teilstaaten gültigen Gesetzeskodifikationen abzuweichen; daß bei der „Bearbeitung " dann verstärkt sowjetische Elemente in die Justizgesetze eingebaut würden, war abzusehen ${ }^{16}$. Insofern diente das Memorandum keineswegs nur dazu, „Überspitzungen ' in der Arbeit des Staatsapparates der DDR zu eliminieren "17, sondern wies gleichzeitig in Richtung Sowjetisierung des deutschen Justizwesens.

Dieses sowjetische Memorandum veranlaßte das Sekretariat dazu, am 5. November erneut die „Arbeit des Justizapparates“ auf die Tagesordnung zu setzen. Die sowjetischen Anregungen aufgreifend, beschloß es, das „Material über die Mißstände in der Justiz" - die aus dem SKK-Memorandum entnommen werden konnten - den Politbüro- und Sekretariatsmitgliedern zuzustellen, und beauftragte Plenikowski, eine Beratung mit den Spitzen der Staatsanwaltschaft aus den Ländern und der Zentrale durchzuführen; die Generalstaatsanwälte der Länder hatten innerhalb von zwei Wochen „über alle Fälle, wo Untersuchungsgefangene sich längere Zeit in Haft befinden, ohne daß ein ordnungsgemäßes Verfahren durchgeführt wird, zu berichten“. Der vierte Beschluß, mit dem die Abteilung Staatliche Verwaltung beauftragt wurde, die Parteiorganisationen der Justizbehörden "gegen diese Mißstände zu mobilisieren“, verband die sowjetischen Anweisungen mit der SED-Forderung, die Parteiaktivitäten in der Justiz zu verstär$k^{18}{ }^{18}$. In den folgenden Wochen versuchten MdJ und Oberste Staatsanwaltschaft, mit einzelnen Maßnahmen die Verkürzung der langen Untersuchungshaften und eine Beschleunigung der Verfahren zu erreichen ${ }^{19}$; der Minister für Staatssicherheit erließ am 6. November 1951 Befehl Nr. 57/51, mit dem er genauere Ermittlungen anordnete, um nicht zu viele Häftlinge aus Mangel an Beweisen entlassen zu müssen'20.

Dies schien den Verantwortlichen aber nicht auszureichen. Durch die sowjetische Intervention fühlten sie sich vielmehr veranlaßt, ihre im Oktober im Sekretariat und Ministerrat verabschiedeten, sich vielfach überschneidenden Maßnahmepläne erneut hervorzuholen und mit den sowjetischen Anweisungen zu einem Gesamtkonzept zu verbinden. Am 20. November 1951 behandelte erstmals das Politbüro das Thema „Verbesserung der Arbeit der Justiz“ und ließ sich einleitend von Grotewohl und Plenikowski Bericht erstatten. Das Politbüro traf eine Reihe von Einzelentscheidungen, die entweder bereits Veranlaßtes wiederholten und weiterentwickelten oder direkte Auswirkungen des sowjetischen Memorandums waren: $\mathrm{Zu}$ ersteren zählten die Umwandlung der Zentralen Richterschule in eine Hochschule der Justiz, die Verstärkung der Abteilung Schulung im MdJ, die Bildung des Instituts für Rechtswissenschaft, die Verstärkung der leitenden Funk-

16 Die Neukodifizierung des GVG, der StPO und des StGB sind daher auf diese sowjetische Anweisung zurückzuführen. Die 2. SED-Parteikonferenz vom Juli 1952 beschloß, ein Arbeitsgesetzbuch, ein Zivilgesetzbuch und ein Strafgesetzbuch ausarbeiten zu lassen: Protokoll der II. Parteikonferenz, S. 493. Ein sowjetischer Ursprung dieses Beschlusses ist nicht nachweisbar, aber wahrscheinlich; zur ersten Etappe der Ausarbeitung des neuen Zivilgesetzbuches vgl. Flinder, Entstehungsgeschichte, S. 21-48.

17 So Lemke, Sowjetisierung der SBZ/DDR, S. 49.

18 Protokoll der Sekretariatssitzung, 5. 11. 1951, SAPMO, DY 30 J IV 2/3/245, TOP 2.

19 Vgl. die Arbeitstagungen im MdJ und bei der OStA zum Thema: „Die langen Untersuchungshaften“, BAB, DP1 VA Nr. 6231; Scheele an Tzschorn, SAPMO, NY 4090/301, Bl. 55, 56-59; BAB, DP3 Nr. 25, Bl. 413-30.

20 MfS-Befehl Nr. 57/51, BStU, MfS DSt. 100013. 
tionen im Justizministerium und die Verbesserung von dessen justizsteuernder Tätigkeit; letztere beinhalteten einen Auftrag an den Generalstaatsanwalt, „die politische Erziehungsarbeit unter den Staatsanwälten zu organisieren“, und die Anweisung zur Ausarbeitung einer „Direktive über die Anwendung des Jugendgerichtsgesetzes“. Am wichtigsten war jedoch der Auftrag an eine aus Grotewohl, Zaisser, Fechner, Plenikowski, Benjamin, Melsheimer und Böhme zusammengesetzte Kommission, „ein einheitliches Dokument über die Verbesserung der Arbeit der Justiz zur Beschlußfassung auszuarbeiten und dem Politbüro vorzulegen"21. Die dem Protokoll beigefügten und der Kommission zur Verfügung gestellten Arbeitsmaterialien umfaßten alle seit September 1951 von SED-Gremien und dem MdJ erstellten und verabschiedeten Dokumente ${ }^{22}$, nicht aber das SKKMemorandum. Daß im zentralen SED-Apparat Überlegungen zur Umsetzung der Weisungen aus Karlshorst angestellt wurden, zeigt eine ebenfalls in den Papieren Grotewohls vorhandene, nicht gezeichnete Aktennotiz von Ende November: Wahrscheinlich war dies die Form, in der das SKK-Memorandum Eingang in den nun erarbeiteten Justizbeschluß des Politbüros fand ${ }^{23}$. Das Arbeitsergebnis der Kommission bildete eine von Plenikowski unterzeichnete Vorlage vom 7. Dezember $^{24}$, die das Politbüro vier Tage später behandelte. In der Sitzung selbst wurden eine Reihe von Änderungen vorgenommen, die Plenikowski im Auftrag des Politbüros in die Endfassung des verabschiedeten Dokuments einarbeitete ${ }^{25}$; eine Reihe von Indizien deuten darauf hin, daß vor der Endredaktion auch die SKK nochmals in den Text des Beschlusses eingriff.

Der endgültige Text des 19seitigen Dokuments wurde auf Wunsch des Politbüros mit einer Zusammenfassung der Kritik an der Arbeit des Justizapparats eingeleitet. Der eigentliche Beschluß bestand aus fünf Teilen, die sich mit der „Verbesserung der Parteiarbeit“ (I), „Maßnahmen zur Hebung des ideologischen Niveaus der Mitarbeiter der Justiz“ (II), „Maßnahmen zur Verbesserung der kaderpolitischen Zusammensetzung des Justizapparates“ (III), „Verbesserung der operativen Arbeit" (IV) und „Gesetzgebung“ (V) befaßten. Unter Punkt I wurden unter anderem eine Parteiaktivtagung mit allen Sekretären der Parteiorganisation in der Justiz, eine regelmäßige Kontrolle der Parteiorganisation der Justizbehörden, die Verstärkung des Justizsektors beim ZK und die Ausstattung der Landesleitungen mit zwei Justizinstrukteuren beschlossen. Der zentrale Satz dieses Abschnitts lautete: „Die Parteiorganisation muß mehr als bisher zu einer wirklichen Kraft im Justizapparat werden, auf die sich die verantwortlichen Genossen in der Durchführung ihrer Arbeit stützen können. " Die Vorgaben der oberen Parteiinstanzen sollten folglich durch eine entsprechende Tätigkeit an der Basis ergänzt werden. Zur „Hebung des ideologischen Niveaus“ der Justizmitarbeiter (II) war vor allem das Schulungssystem zu reformieren und zu vervollständigen: Dabei ging es unter anderem um die innerbetriebliche Schulung, die Gründung der Deutschen Hoch-

21 Protokoll der Politbürositzung, 20. 11. 1951, SAPMO, DY 30 J IV 2/2/178, TOP 2.

22 Siehe die Anlagen zu TOP 2, ebenda, Bl. 7-25.

23 Aktennotiz, Abschrift vom 29. 11. 1951, SAPMO, NY 4090/301, Bl. 77-80.

24 Vorlage für Politbüro, 7. 12. 1951, ebenda, Bl. 103-119.

25 Protokoll der Politbürositzung, 11. 12. 1951, SAPMO, DY 30 J IV 2/2/182, TOP 6, Anlage Nr. 3. Die Beschlüsse unter TOP 6 gedruckt in: Dreier u.a., Rechtswissenschaft, S. 49; Anlage 3 auszugsweise, ebenda, S. 52-56. 
schule der Justiz, die Durchführung der unterschiedlichsten Lehrgänge, den Fernunterricht sowie die Gründung des Instituts für Rechtswissenschaften, das eine theoretisch-juristische Zeitschrift herausgeben sollte. Teil III legte eine umfassende Überprüfung aller Justiz- und Untersuchungsorgane im Hinblick auf ihr Personal fest. Die Endfassung dieses Punktes wich insofern von der Vorlage ab, als dazu die Bildung von zwei Kommissionen vorgesehen wurde, von denen eine umgehend mit der Überprüfung der für die politischen Strafsachen zuständigen Staatsanwaltschaften und Gerichte beginnen sollte. Da dies in dem Memorandum der SKK angemahnt worden war, läßt sich auch diese Änderung aller Wahrscheinlichkeit nach auf eine sowjetische Intervention zurückführen. Des weiteren ging es um die Neubesetzung wichtiger Positionen bei der Obersten Staatsanwaltschaft, beim Obersten Gericht und im MdJ ebenso wie um die Erhöhung der Teilnehmerzahl an den Lehrgängen der Justizhochschule von 400 auf 600 und um eine Überprüfung der fortgeschrittenen Jurastudenten.

Am auffälligsten waren die Änderungen in den ersten beiden Unterpunkten der Ausführungen zur „Verbesserung der operativen Arbeit“. Während die Vorlage unter Punkt IV.1 genaue Fristen bei der Durchführung von Strafverfahren nannte, hielt die Endfassung lediglich fest, daß die vom DDR-Generalstaatsanwalt und Justizminister festzulegenden Zeitspannen so beschaffen sein müßten, „daß eine verantwortlichere, bessere und schnellere Durchführung der Verfahren in kürzester Frist gewährleistet ist“. Der SKK, der offensichtlich die ursprünglich festgelegten Fristen zu großzügig bemessen waren, hoffte die Verfahren durch diese Anweisung noch stärker zu beschleunigen. Noch deutlichere Veränderungen wurden an den Vorschriften für Festnahmen und Verhaftungen vorgenommen. Die Vorlage unterschied deutlich zwischen politischen und sonstigen Strafsachen: Nur im letzteren Fall hatten sich Festnahmen und Haftbefehle „ausschließlich nach den Vorschriften der Strafprozeßordnung" zu richten, während bei "Strafsachen des Dezernats I“, in denen das MfS ermittelte, Befehl Nr. 201 mit seinen Ausführungsbestimmungen gelten sollte, um dem Staatssicherheitsdienst seine weitreichenden Möglichkeiten zu Verhaftungen ohne richterlichen Haftbefehl zu erhalten. Die Endfassung schrieb hingegen vor, daß die Vorschriften der Strafprozeßordnung für alle Festnahmen zu gelten hatten. Als einziges Zugeständnis an das MfS sollten bei jedem Landgericht „besonders qualifizierte und überprüfte Richter" zum Erlaß von Haftbefehlen gegen politische Straftäter bestellt werden. Auch hier war die SKK offensichtlich eingeschritten, um die Willkürakte des MfS zu begrenzen. Kaum Abweichungen von der Vorlage gab es bei den anderen Regelungen über prozessuale Fragen, die die richtige Durchführung des Eröffnungsbeschlusses, Verfahren vor erweiterter Öffentlichkeit und am Tatort und die Einhaltung der gesetzlichen Fristen bei der Urteilsabsetzung betrafen. Auch die im $\mathrm{Zu}$ sammenhang mit der Steuerung der Justiz stehenden Maßnahmen blieben weitgehend unverändert: Vorgesehen waren ein die Rundverfügungen des MdJ enthaltendes „Handbuch für den Strafrichter“, Quartalsarbeitspläne für die Gerichte und die Verbesserung der operativen Tätigkeit des MdJ'6. Teil IV enthielt überdies 
noch die Anweisungen, alle Haftanstalten ab dem 1. Juli 1952 der Polizei zu unterstellen, Richtlinien zum Arbeitseinsatz von Strafgefangenen aufzustellen und per Ministerratsbeschluß den Generalstaatsanwalt mit der Aufsicht über alle gerichtlichen Voruntersuchungen und über alle Strafanstalten zu beauftragen.

In Teil V schließlich waren lediglich die Ausführungen zur Ausarbeitung des Jugendgerichtsgesetzes in die Endfassung übernommen worden. Völlig umgearbeitet war die Partie, die sich auf die "Vorbereitung weiterer neuer Gesetze“ bezog. In der Vorlage wurde trotz anderslautender sowjetischer Vorgaben vom November die Ausarbeitung eines Staatsanwaltschaftsgesetzes und die Änderung des Strafgesetzbuches, des Gerichtsverfassungsgesetzes und der Strafprozeßordnung als „nicht wünschenswert“ bezeichnet: Verwiesen wurde dabei darauf, daß gerade bei der Justizgesetzgebung „möglichst jede Änderung vermieden worden [sei], um die formale Rechtseinheit Deutschlands auf diesem Gebiete aufrecht zu erhalten [sic]“. Wahrscheinlich war es für die führenden Genossen äußerst verwirrend, daß die SKK in ihren Anweisungen vom November in der Frage der Justizgesetze eine andere Linie verfolgte. Schon vor dem 11. Dezember muß aus Karlshorst die Weisung gekommen sein, diesen Punkt zu ändern. Denn bei der Politbürositzung wurde bereits entschieden, diese Gesetze durch eine Partei- und eine Regierungskommission dahingehend überprüfen zu lassen, ob sie "neu geschaffen oder nur neu gefaßt werden sollten“. Daß die SKK keine eindeutigere Weisung gab, deutet darauf hin, daß auch sie sich noch nicht ganz klar darüber war, wie weit die Änderungen bei den Justizgesetzen gehen sollten; durch die Abkehr von der bisher verfolgten Linie wurde jedoch ein weiterer Schritt weg von der Rechtseinheit Deutschlands eingeleitet.

Unmittelbar nach Verabschiedung des Politbürobeschlusses machten sich SED und MdJ an dessen Umsetzung. Bereits am 13. Dezember wurde durch Sekretariatsbeschluß der Strukturplan der Abteilung Staatliche Verwaltung um zwei wissenschaftliche Mitarbeiterstellen - eine für Rechtswissenschaft und eine andere für Staatswissenschaften - erweitert; der Sektor Justiz erhielt am 17. Januar 1952 mit Richard Spank einen neuen Leiter sowie einen weiteren Instrukteur (Herbert Kern), so daß dieser erstmals über insgesamt drei Instrukteure verfügte ${ }^{27}$. Der Arbeitsplan der Abteilung Staatliche Verwaltung für das erste Quartal 1952 konkretisierte auch direkt einige Aufgaben aus dem Justizbeschluß: Landgericht und Oberstaatsanwaltschaft Magdeburg sollten durch zwei „zentrale Brigaden“ zur vorbildlichen Arbeit angeleitet werden; aus dem ersten Sonderlehrgang zur Gewinnung von Leitungspersonal wollte der SED-Justizsektor Personen zur „kadermäßigen Verstärkung “ der Obersten Staatsanwaltschaft, des Obersten Gerichts und des MdJ auswählen und die Abteilung Personal und Schulung des Justizministeriums stärker unter seine Fittiche nehmen ${ }^{28}$. Die geplanten Überprü-

von Einzelmaßnahmen vor, die Endfassung nur eine vierteljährliche Revision eines Gerichts und einer Staatsanwaltschaft in jedem Land.

27 Siehe Protokoll der Sekretariatssitzungen, 13. 12. 1951, 17. 1. 1952, SAPMO, DY 30 J IV 2/3/254, TOP 3, 2/3/262, TOP 24 . Neben Kern waren noch Fuchs und Reisler als Instrukteure im SEDJustizsektor tätig.

28 Das Sekretariat verabschiedete den Arbeitsplan am 13.12. 1951: SAPMO, DY 30 J IV 2/3/254, TOP 1, Anlage Nr. 3. 
fungen in Magdeburg fanden termingerecht statt ${ }^{29}$, und das Sekretariat bestätigte am 14. Februar vier neue Richter des Obersten Gerichts und im Verlauf des Monats April insgesamt dreizehn neue Staatsanwälte für die Oberste Staatsanwaltschaft ${ }^{30}$. Die Errichtung eines zentralen Instituts für Rechtswissenschaft wurde mit Sekretariatsbeschluß vom 4. Februar vorangetrieben ${ }^{31}$. Probleme bereitete offensichtlich die vom Politbüro geforderte „Direktive an die Landes- und Kreisleitungen für die Arbeit der Parteiorganisationen im Justizapparat": Am 27. März 1952 wurde ein erster Entwurf zurückgewiesen und am 10. April endgültig abgelehnt. Als Ersatz griff man auf die Broschüre, die zur Auswertung der Parteiaktivtagung vom 19. Januar 1952 gedruckt werden sollte, zurück ${ }^{32}$. Fechner zog für den Ministerrat am 27. März eine überwiegend positive Bilanz der Arbeit seines Ministeriums seit Oktober 1951. Dabei konnte er insbesondere auf Schulungsmaßnahmen, auf die zunehmende Zentralisierung der Personalpolitik beim MdJ und auf eine Reihe von Planungen, Anweisungen und Rundverfügungen im Hinblick auf prozessuale Details und die Justizsteuerung verweisen. Der Ministerrat nahm seine Ausführungen „zustimmend zur Kenntnis“33.

Diese Aktivitäten beschränkten sich jedoch weitgehend auf die Apparate und wirkten sich noch kaum auf die Justizpraxis aus. Die Gerichte und Staatsanwaltschaften sowie das Justizministerium waren daher auch weiterhin heftiger, nun sogar öffentlich geäußerter Kritik ausgesetzt. Anfang April 1952 erschien auf der ersten Seite des „Neuen Deutschland“ ein langer Artikel „Zur Arbeit unserer Justizorgane“ ${ }^{34}$. Den Justizbehörden wurde zum einen mangelnde Effizienz vorgeworfen, was sich vor allem in der Nicht-Einhaltung der gesetzlich vorgesehenen Fristen und der zeitlichen Ausdehnung der Untersuchungs- und Gerichtsverfahren äußere. Zum anderen unterstellte der Artikel einigen Gerichten, daß sie durch Nichtbeachtung von Gesetzen "Schieber und Spekulanten“ deckten. Die Justizorgane, so der generelle Vorwurf, hätten „die wirklichen Schwerpunkte in ihrer Arbeit" - Schutz der staatlichen Ordnung, des wirtschaftlichen Aufbaus und der Bürger „vor verbrecherischen und feindlichen Elementen“ - nicht erkannt. Die Verantwortung dafür trage im wesentlichen das MdJ. Dort herrsche „eine Atmosphäre der Sorglosigkeit und Selbstgefälligkeit, einer bürokratischen Erledigung der Arbeit, die die Sachen dem Selbstlauf überläßt, anstatt den Funktionären im Justizapparat Anleitung und Hilfe zu geben". Es handelte sich offensichtlich um eine Auftragsarbeit, die die Auffassung der Parteispitze wiedergab; sonst hätte eine derart heftige Kritik nicht an einer so prominenten Stelle veröffentlicht werden können.

29 Protokoll der Abteilungsleitersitzung im MdJ, 1. 2. 1952, BAB, DP1 VA Nr. 1117, Bl. 24 f.; Bemerkungen zur Abteilungsleitersitzung am 1. 2. 1951, BAB, DP1 VA Nr. 6967.

30 Protokolle der Sekretariatssitzungen am 14. 2., 3. 4., 24. 4. 1952, SAPMO, DY $30 \mathrm{~J}$ IV 2/3/269, TOP 18,280 , TOP 11,285 , TOP 14.

31 Protokoll der Sekretariatssitzung, 4. 2. 1952, SAPMO, DY 30 J IV 2/3/266, TOP 15, Anlage Nr. 3.

32 Protokoll der Sekretariatssitzungen am 27. 3. und 10. 4. 1952, SAPMO, DY 30 J IV 2/3/278, TOP 54 und 282, TOP 2. Für die Broschüre siehe Plenikowski, Aufgaben. Abschnitt VI, S. 37-50, behandelt ausschließlich „Die Verwirklichung der führenden Rolle der Partei“.

33 Protokoll der Regierungssitzung, 27. 3. 1952, BAB, DC 20 I/3 Nr. 100, TOP 1, Bl. 3 f. Fechners Bericht, den er am 25. 3.1952 an das Sekretariat des Ministerpräsidenten übersandte, in: BAB, DP1 VA Nr. 6187, Nr. 263.

34 Neues Deutschland, 4. 4. 1952. 
Kritik kam außerdem aus Karlshorst. In einem weiteren Memorandum, das Mitte Mai Grotewohl übergeben wurde ${ }^{35}$, beanstandete die SKK, daß trotz ihrer Anweisungen vom November 1951 die Arbeit der Untersuchungsorgane und der Justiz „noch ernste Mängel“ aufweise. Die Untersuchungsorgane seien noch nicht "gesäubert" und aus den Überprüfungen der politischen Kammern der Landgerichte noch nicht die notwendigen Konsequenzen gezogen worden; die Regelung der Fristen für die Untersuchungs- und Gerichtsverfahren sei nach wie vor unbefriedigend; in einigen politischen Fällen seien die Gerichte zu nachsichtig verfahren, die Gesetzgebungsverfahren im Hinblick auf das Jugendstrafrecht sowie das Staatsanwaltschaftsgesetz $z^{36}$ und die Überprüfung des Gerichtsverfassungsgesetzes, der Strafprozeßordnung und Strafgesetzbuches kämen nicht voran. Die SKK warf zudem Justizminister Fechner vor, erst im März mit der Auswahl der Haftrichter für politische Sachen begonnen zu haben und über die Besetzung der Gerichte nur unzureichend informiert zu sein; Staatssicherheitsminister Zaisser habe den Justizbeschluß, der ja auch die Untersuchungsbehörden betreffe, mißachtet und immer noch keine Büros eingerichtet, die Auskünfte über Inhaftierte erteilen sollten. Diese erneute Intervention der SKK im Zusammenhang mit der Umsetzung des Justizbeschlusses zeigt, daß es darin um zentrale Anliegen ihrer Politik ging. Aus dem Vergleich der Memoranden vom November 1951 und vom Mai 1952 ergibt sich freilich eine Schwerpunktverlagerung der sowjetischen Politik. Zwar bezog sich die SKK im Mai 1952 ausdrücklich auf einige der sechs Monate zuvor erhobenen Forderungen zur Regulierung der (geheim)polizeilichen und justitiellen Repression; indem sie sich jedoch voll und ganz hinter den SED-Justizbeschluß stellte und nochmals ausdrücklich auf die mangelnde Härte einiger Urteile in politischen Sachen verwies, zeigte sie, daß es auch ihr primär um die Effektivierung der Arbeit des Justizapparats im Sinne der SED ging. Verstärkt wurde die bereits im Memorandum vom November 1951 anklingende Tendenz zur Sowjetisierung der Verhältnisse im Justizwesen der DDR. Um die Justiz wirksam in den Dienst der Politik nehmen zu können, war sowohl für die SED als auch für die sowjetischen Herrschaftsträger die Übernahme sowjetischer Strukturen letztlich unvermeidbar.

In diesen Kontext fügt sich die intensivierte Rezeption sowjetischer Rechtstheorie und Rechtswissenschaften in den Jahren 1951/52 ein. Aufmerksame Leser konnten feststellen, daß ab Mitte 1951 in der „Neuen Justiz“ keine westdeutschen Bücher mehr rezensiert wurden, es sei denn, daß sie sich besonders eigneten, die westliche Rechtswissenschaft als "faschistisch“ und „imperialistisch“ zu entlarven; ab 1952 wurde die bürgerliche Rechtswissenschaft in dieser Zeitschrift völlig

35 Memorandum in: NY 4090/440, Bl. 217f., Übersetzung Bl. $211 \mathrm{f}$. Die Übersetzung trägt den handschriftlichen Vermerk Grotewohls: „An Ulbricht u. Zaisser schreiben 15/5 G." Gedruckt bei Mollnau, Staatsanwaltschaftliche Gesetzlichkeitsaufsicht, S. 268-270.

36 Diese Gesetzgebungsvorhaben standen bei Überreichung des Memorandums kurz vor dem Abschluß: Sekretariat und Politbüro hatten dem Jugendgerichtsgesetz und dem Staatsanwaltschaftsgesetz am 5. und 13. Mai zugestimmt: Protokoll der Sekretariatssitzung, 5. 5. 1952, SAPMO, DY $30 \mathrm{~J} \mathrm{IV} \mathrm{2/3/287,} \mathrm{TOP} 15$ und 16; Protokoll der Politbürositzung, 13. 5. 1952, SAPMO, DY $30 \mathrm{~J}$ IV 2/2/211, TOP 9 und 10 . 
ausgeblendet ${ }^{37}$. 1951 erschienen zudem im SED-eigenen Dietz-Verlag Andrej Wyschinskis „Gerichtsreden“: Es handelte sich um zehn Anklagereden, die der ehemalige sowjetische Generalstaatsanwalt vor allem bei Schauprozessen der dreiBiger Jahre gehalten hatte ${ }^{38}$. Benjamin, die in Wyschinski ihr großes Vorbild sah und diesen auch in seinem äußeren Habitus nachzuahmen versuchte ${ }^{39}$, pries sie als „eine außerordentlich wichtige, lehrreiche und packende Veröffentlichung" an: „Die Gerichtsreden Wyschinskis lehren uns die vielfältigen Methoden erkennen, die die Gegner des Fortschritts und der Demokratie im Klassenkampf anwenden, sie lehren die unerbittliche und kompromißlose Bekämpfung der Klassenfeinde. " 40 Für sie spielte daher bei der Wyschinski-Rezeption die Rechtspraxis eine wichtige Rolle; für die DDR-Rechtswissenschaft ist vor allem die Übernahme von Wyschinskis positivistischem und rein instrumentellem Rechtsbegriff hervorzuheben, die unter anderem bei Hermann Klenner nachweisbar ist ${ }^{4}$.

Ungleich wichtiger für die Rechtswissenschaft - und für alle anderen Wissenschaften in der sowjetisch dominierten Staatenwelt - wurden einige Bemerkungen in der kleinen Schrift Stalins vom Juni 1950 „Über den Marxismus in der Sprachwissenschaft", die ebenfalls 1951 erstmals in deutscher Übersetzung erschien. Entscheidend waren nicht Stalins Ausführungen zur Sprachwissenschaft selbst, sondern seine Bemerkungen zum Verhältnis von Basis und Überbau gemäß der marxistischen Lehre. Dabei bildete das marxistische Dogma, daß der Überbau, zu dem er „die politischen, juristischen, religiösen, künstlerischen, philosophischen Anschauungen" zählte, von der Basis abhängig sei, lediglich seinen Ausgangspunkt. Denn „einmal auf die Welt gekommen, wird er [der Überbau] zu einer gewaltigen aktiven Kraft“. Dem Überbau gestand Stalin folglich eine aktive Rolle in dem revolutionär verlaufenden Geschichtsprozeß zu, da dieser an der Beseitigung "der alten, überlebten Basis“ unmittelbar beteiligt sei42. Letztlich handelte es sich dabei um eine Legitimation der ,Revolution von oben', wie sie in allen Staaten im sowjetischen Machtbereich nach dem Vorbild der Sowjetunion praktiziert wurde. Auf das hier interessierende Teilgebiet des „Überbaus“ angewandt, bedeutete dies, $\mathrm{da} ß$ das Recht nicht länger ausschließlich als abgeleitete Kategorie angesehen, sondern aufgewertet wurde, da es nun als "Waffe für den Aufbau der sozialistischen Gesellschaft" diente43. Da der Weg zum Sozialismus jedoch nur unter der Führung der kommunistischen Partei beschritten werden konnte, war sie es letztlich, die die Gestalt des Rechts und seiner Anwendung bestimmte. Letztlich lieferten Stalins Äußerungen damit auch die Legitimation für die völlige Vereinnahmung der Rechtswissenschaft durch die SED.

$37 \mathrm{Vgl}$. Markovits, Sozialistisches und bürgerliches Zivilrechtsdenken, S. 11 f.; Diestelkamp, Zur Rolle der Rechtswissenschaft, S. 90.

38 Wyschinski, Gerichtsreden.

39 Vgl. Feth, Benjamin, S. 116-118.

40 Benjamins Rezension der "Gerichtsreden“ in: Einheit 7 (1952), S. 699-703, hier 699. Die Lektüre der "Gerichtsreden" war für sie „die erste bewußte Begegnung mit Wyschinski“: siehe Benjamin, Wyschinski, S. 691.

${ }^{41}$ Vgl. Schönfeldt, Geschichte der Rechtswissenschaft, S. 230f.; Klenner, Marxismus-Leninismus über das Wesen des Rechts, S. 8, 88; Mollnau, Sozialistische Gesetzlichkeit, S. 73 f.

42 Stalin, Über den Marxismus, S. 4-6.

43 So Böckenförde, Rechtsauffassung, S. 29. 
Die Rezeption von Stalins Schrift in der DDR wurde von der SED bis ins kleinste Detail gesteuert. Den Auftakt bildete eine von der ZK-Abteilung Propaganda einberufene theoretische Konferenz am 23./24. Juli in Berlin, bei der Fred Oelßner das Hauptreferat hielt. In seinem Schlußwort schlug er vor, gegen Jahresende zur konkreten Auswertung der Schriften Stalins in den einzelnen Wissenschaftszweigen Tagungen abzuhalten ${ }^{44}$. Für die SED-Juristen, deren mangelnde Beteiligung an der Vorbereitung der Veranstaltung vom Juni Hilde Benjamin öffentlich kritisierte, wurde im November/Dezember ein theoretischer Kongreß ins Auge gefaßt, der durch eine Reihe von Vorkonferenzen beim Obersten Gericht, bei der DVA und bei den juristischen Fakultäten in Leipzig und Jena vorbereitet wurde ${ }^{45}$. Die endgültige Entscheidung über den Juristenkongreß traf das Sekretariat am 8. November 1951, das als Datum den 15./16. Dezember und als Referentin Hilde Benjamin bestimmte. Dem SED-Führungsgremium genügte es nicht, eine überzeugte und linientreue Genossin beauftragt zu haben, sondern es bestand auch noch darauf, das Hauptreferat in Thesenform bis zum 1. Dezember vorgelegt zu bekommen ${ }^{46}$. Die Disposition für das Referat wurde dann nach einer entsprechenden Entscheidung Grotewohls am 11. Dezember sogar im Politbüro behandelt ${ }^{47}$. Auf der Konferenz vom 15./16. Dezember wandte Benjamin „Stalins geniale Arbeiten über den Marxismus in der Sprachwissenschaft “ im gewünschten Sinne auf die Rechtswissenschaft an: Stalins Lehre sei „zum entscheidenden Impuls geworden, der nun endlich unsere Rechtswissenschaft befähigt, ihre Aufgabe als Teil des Überbaus zu erkennen und demgemäß zu handeln“. Zu deren wichtigsten Aufgaben gehörten "die Ausmerzung aller imperialistischen Rechtsanschauungen“ sowie „die Hebung des demokratischen Rechtsbewußtseins unserer Bürger“. Letztere Zielsetzung verweist darauf, daß eine Änderung nicht nur der sozioökonomischen Verhältnisse, sondern auch des menschlichen Bewußtseins, also die Aufhebung von Recht und Moral, angestrebt wurden ${ }^{48}$. Das zuerst genannte Vorhaben ließ zunächst noch offen, was denn an Stelle der bürgerlichen Rechtswissenschaft zu treten hatte. Wenn Benjamin damit schloß, daß es ihr um die Konzipierung "einer deutschen Rechtswissenschaft“ zu tun war, so hatten diese Worte vor allem eine auf den Westen ausgerichtete propagandistische Funktion ${ }^{49}$; wie ihr Konzept nahelegt, ging es vielmehr um eine Angleichung der Rechtswissenschaft an die der UdSSR ${ }^{50}$. Dadurch erhielt das von den SED-Führungremien seit Oktober 1951 geplante rechtswissenschaftliche Institut seine zentrale Aufgabe. Die Sowjetisierung der Rechtswissenschaft und deren durch den SED-Justizbeschluß vorangetriebene Institutionalisierung auf zentraler Ebene bedingten einander: Erst durch die Rezeption der Stalin-Schrift erhielt die Rechtswissenschaft in der

44 Vgl. Theoretische Konferenz über das Werk Stalins; der Passus über die Folgekonferenzen S. 853.

45 Benjamin, Theoretische Konferenz, S. 324; Polak, Zur Theoretischen Konferenz, S. 532.

46 Protokoll der Sekretariatssitzung, 8. 11. 1951, SAPMO, DY 30 J IV 2/3/246, TOP 10.

47 Notiz Stempels für Grotewohl, o.D., [Dezember 1951], SAPMO, NY 4090/301, Bl. 136; Büro des Sekretariats an Mitglieder des Politbüros, 10. 12. 1951, ebenda, Bl. 155; Protokoll der Politbürositzung, 11. 12. 1951, SAPMO, DY 30 J IV 2/2/182, TOP 7.

$48 \mathrm{Vgl}$. Böckenförde, Rechtsauffassung, S. $38 \mathrm{f}$.

49 Die Zitate nach Polak, Bericht über die theoretische Konferenz, S. $9 \mathrm{f}$.

50 Die gegenwärtigen Aufgaben der deutschen Staats- und Rechtswissenschaft, NY 4090/301, Bl. 156-173, hier 172: „IV. Wege zur Lösung dieser Aufgabe: 1. Stalin, 2. Marxismus-Leninismus als Grundlage jeder Wissenschaft, 3. Die sowjetische Wissenschaft". 
DDR wieder eine echte Daseinsberechtigung, die ein solches Institut auch theoretisch legitimierte; gleichzeitig bildete eine derartige Institutionalisierung Voraussetzung und Instrument zur Sowjetisierung der Rechtswissenschaft in dem östlichen deutschen Teilstaat.

\section{Die Reise führender SED-Justizkader in die Sowjetunion und die Konsequenzen}

\section{Die Reise in die Sowjetunion}

Die weitgehende Übernahme sowjetischer Strukturen im Justizwesen erlebte in der zweiten Hälfte des Jahres 1952 einen Höhepunkt. Vorangegangen war Ende Mai/Anfang Juni die fünfzehntägige Reise einer hochrangigen SED-Juristendelegation, die „zum Studium der Justizorgane“ 51 in die Sowjetunion entsandt worden war. Deren Vorgeschichte ist weitgehend unbekannt, so daß insbesondere die Frage, ob sie auf eine sowjetische Anweisung oder auf das Drängen der SED-Führung zurückging, offen bleiben muß. Über solche Informationsbesuche versuchte die Sowjetunion seit 1948/49 die Verhältnisse in der DDR zu beeinflussen ${ }^{52}$. 1952/ 53 fanden zahlreiche Reisen dieser Art statt; vermutlich war es kein Zufall, daß das Sekretariat am 17. März 1952 nicht nur die Entsendung einer Delegation von SED-Juristen, sondern auch eine Reise von SED-Verwaltungsfachleuten in die Sowjetunion in die Wege leitete ${ }^{53}$. Bei der Formulierung des Arbeitsauftrags der Juristendelegation war ein Zusammenhang mit dem SED-Justizbeschluß unverkennbar. Die SED-Juristen hatten sich im Rahmen ihres Studiums der „Aufgaben und Arbeitsweise des Justizministeriums" mit Gesetzgebung, Kontrolle der Rechtsprechung, Fragen der Aus- und Weiterbildung sowie Struktur und Arbeitsweise der rechtswissenschaftlichen Institute zu befassen: Von den Gesetzgebungsfragen abgesehen, standen alle diese Themen auch auf der vom SED-Politbüro festgelegten Agenda für das DDR-Justizwesen. Auch Arbeitsweise und Aufbau der Gerichte und Staatsanwaltschaften waren von den DDR-Juristen besonders zu studieren: Angesichts der vor allem von der SKK angestoßenen Arbeiten zur Erstellung eines Staatsanwaltschaftsgesetzes sowie der Neukodifikation der Strafprozeßordnung, des Gerichtsverfassungsgesetzes und des Strafgesetzbuches war der SED-Führung besonders in diesem Zusammenhang daran gelegen, das sowjetische Vorbild in Augenschein zu nehmen.

Die SKK führte die SED bei der Durchführung dieser Arbeiten am kurzen Zügel. Denn nach der Konstituierung der Kommission zur Überprüfung der Justizgesetze am Vormittag des 13. Februar 1952 unter Benjamins Vorsitz betonte Oberst Titow gegenüber der neu ernannten Kommissionsvorsitzenden am Abend desselben Tages die große politische Bedeutung dieser Arbeiten, „für die sich der Chef der SKK, Tschuijkow, unmittelbar interessiere“. Die Kommission, so Titow,

51 So die Formulierung von TOP 17 im Protokoll der Sekretariatssitzung, 17. 3. 1952, SAPMO, DY 30 J IV 2/3/275.

52 Vgl. Kaiser, Sowjetischer Einfluß, S. 121-123.

53 Protokoll der Sekretariatssitzung, 17.3. 1952, SAPMO, DY 30 J IV 2/3/275, TOP 17 und 18. 
solle einen Arbeitsplan aufstellen, der für jedes ihrer Mitglieder die genaue Aufgabenstellung und genaue Termine enthalten müßte ${ }^{54}$. Bei einer weiteren Unterredung am 1. März drängte Titow auf Beschleunigung der Arbeiten sowie auf die weitgehende Befreiung der Kommissionsmitglieder von ihren sonstigen Tätigkeiten; außerdem wollte er in regelmäßigen, etwa zehntägigen Abständen mit Benjamin „über den Fortgang der Arbeiten sprechen“; Korobow sollte „die Fühlung mit den Vorsitzenden der Unterkommissionen übernehmen" ${ }^{55}$. Die SED-Kommission stand also unter hohem sowjetischen Erwartungsdruck. Gleichzeitig war sie sich, wie das Protokoll ihrer ersten Sitzung zeigt, noch unsicher im Hinblick auf die Reichweite der Änderungen an GVG, StPO und StGB: Auf den ersten Eindruck hin erschien ihr „ein eventueller Umbau so umfassend [zu] sein [...], daß eine Neufassung dem Umbau vorzuziehen wäre", aber auch dann stellte sich noch die Frage, wie eine solche Neufassung auszusehen hatte ${ }^{56}$.

Die SKK, die über den Fortgang der Beratungen auf dem laufenden gehalten wurde ${ }^{57}$, mahnte in ihrem Memorandum von Mitte Mai zur Beschleunigung. Am 21. Mai beschloß das Sekretariat daher die Neufassung der drei Justizgesetze ${ }^{58}$. Formell sollte aufgrund eines Regierungsbeschlusses eine Kommission zur Ausarbeitung eines neuen Strafgesetzbuches eingesetzt werden; die wiederum hatte zwei Unterkommissionen zur Ausarbeitung eines neuen GVG und einer neuen StPO zu beauftragen. Da dies auf eine weitgehende Anlehnung an das sowjetische Modell hinauslief, kam dem Informationsbesuch der SED-Juristen in der Sowjetunion eine erhöhte Bedeutung zu. Bereits im Vorfeld der Reise war deutlich geworden, daß ein Studium der sowjetischen Justizorgane vor Ort aufgrund des deutlichen Interesses der SKK an einer Neuordnung des DDR-Justizwesens angebracht erschien. Dies entsprach vermutlich auch dem Bedürfnis der SED-Juristen, sich vor einem solchen Schritt nicht nur anhand schriftlicher Unterlagen über das sowjetische Justizwesen zu informieren. Die durch den Justizbeschluß angestoßenen Tätigkeiten und die Initiierung der Reise der SED-Juristendelegation griffen folglich ineinander und dienten demselben Ziel: Die Arbeit des Justizapparates sollte durch dessen Anpassung an die sowjetischen Strukturen in ihrer Wirksamkeit erhöht werden.

Der Informationsbesuch der SED-Juristen wurde - soweit dies aus der Überlieferung der SED-Akten hervorgeht - von der Abteilung Staatliche Verwaltung vorbereitet: Sie arbeitete die Aufgabenstellung aus ${ }^{59}$ und unterbreitete einen Vorschlag über die Zusammensetzung der Delegation, in der sowohl die Zentralinstanzen als auch die Länder (einschließlich Berlins) angemessen vertreten waren. Als Leiterin war Hilde Benjamin vorgesehen; von der Obersten Staatsanwalt-

54 Vermerk Benjamins, 14. 2. 1952, BAB, DP1 VA Nr. 8419.

55 Vermerk Benjamins über die Unterredung mit Titow über das Protokoll vom 1. 3. 1952, 4. 3. 1952, ebenda. Laut Protokoll der Grundkommission zur Überprüfung strafrechtlicher Gesetze vom 1. 3. 1952 wurde damals entschieden, daß jeweils eine Unterkommission sich mit dem StAG, dem GVG, der StPO und dem StGB beschäftigen sollte (ebenda).

56 Ebenda.

57 Vgl. u.a. Benjamin an Titow, 5. 4. 1952, BAB, DP1 VA Nr. 1050, Bl. 727.

58 Protokoll der Sekretariatssitzung, 21. 5. 1952, SAPMO, DY 30 J IV 2/3/291, TOP 5.

59 Siche ein undatiertes Papier aus dieser Abteilung beginnend mit den Worten: „Aufgabe der JustizDelegation wäre das Studium insbesondere folgender Fragen“, SAPMO, DY 30 IV 2/13/448, Bl. 45 . 
schaft kam der stellvertretende Generalstaatsanwalt Kurt Schmuhl, vom Justizministerium Werner Artzt, von der Deutschen Verwaltungsakademie deren Präsident Arthur Baumgarten und vom Deutschen Institut für Rechtswissenschaft dessen Leiter Hans Gerats hinzu. Als Ländervertreter wurden fast durchweg hochrangige Justizfunktionäre vorgeschlagen: aus Sachsen der stellvertretende Landesstaatsanwalt Richard Krügelstein, aus Mecklenburg der Landesstaatsanwalt Walter Schultz, aus Thüringen und Brandenburg die jeweiligen Leiter der Hauptabteilungen Justiz Martin Spranger und Wilhelm Utech und aus Berlin Kammergerichtspräsident Hans Ranke. Nur aus Sachsen-Anhalt wurde mit dem Amtsgerichtspräsidenten von Halle, Gustav Jahn, ein Justizfunktionär der mittleren Ebene ausgewählt. Nach Überprüfung dieser elf Personen durch die Kaderabteilung des zentralen Parteiapparats erfolgte am 25. März ein entsprechender Politbürobeschluß, demzufolge das ZK der KPdSU gebeten wurde, „der Entsendung einer Delegation zum Studium der Arbeit der Justizorgane in die UdSSR zuzustimmen" 60 .

Die Zustimmung aus Moskau traf offensichtlich drei Wochen später in OstBerlin ein; Benjamin jedenfalls wurde am 15. April 1952 von Plenikowski über ihre Teilnahme an der Studiendelegation informiert und für den 21. April zu einer Vorbesprechung ins ZK gebeten ${ }^{61}$. Danach übersandte Benjamin den Delegationsmitgliedern sowie dem Leiter des SED-Justizsektors jeweils eine Abschrift des sowjetischen Gerichtsverfassungsgesetzes ${ }^{62}$, was darauf hindeutet, daß bei den $\mathrm{Pla}^{-}$ nungen die Neukodifikationen sowie Fragen der Gerichtsorganisation im Vordergrund standen ${ }^{63}$. Vor ihrer Abreise erstellten die Teilnehmer - wahrscheinlich in Zusammenarbeit mit der Abteilung Staatliche Verwaltung - ausführliche Arbeitsprogramme zu den einzelnen Themenbereichen Gerichte, Justizverwaltung, Staatsanwaltschaft und wissenschaftliche Arbeit ${ }^{64}$. Die Delegation begab sich schließlich am 28. Mai nach Moskau65, wo sie am darauffolgenden Tag in einer ersten Besprechung im sowjetischen Justizministerium ihre Ausarbeitungen übergab; auf dieser Grundlage erstellten die sowjetischen Genossen einen genauen Arbeitsplan ${ }^{66}$, nach dem die Delegation in den folgenden 15 Tagen verfuhr, bevor sie am 13. Juni in die DDR zurückkehrte ${ }^{67}$.

Die zehnköpfige Juristengruppe aus der DDR - Gustav Jahn aus Halle nahm

60 Protokoll der Sekretariatssitzung, 17.3. 1952, SAPMO, DY 30 J IV 2/3/275, TOP 17; Protokoll der Politbürositzung, 25. 3. 1952, SAPMO, DY 30 J IV 2/2/204, TOP 14.

6t Plenikowski an Benjamin, 15. 4. 1952, vertraulich, BAB, DP1 VA Nr. 6985. Über die Besprechung am 21. 4. existieren nur handschriftliche, stenographische Notizen Benjamins, ebenda.

62 Sekretariat des Obersten Gerichts an Spank, 22. 4. 1952, SAPMO, DY 30 IV 2/13/448, B1. 90; auch Baumgarten, Utech, Artzt und Spranger erhielten bis zum 6.5. 1952 jeweils ein Exemplar des GVG: BAB, DP1 VA Nr. 6985.

63 Vgl. die Überschrift über Benjamins Reisekladde: „Studien und Notizen für die Entwicklung einer demokratischen Prozeßrechtswissenschaft und ein neues demokratisches Prozeßrecht", BAB, DP1 VA Nr. 7675, Bl. 172.

64 Vorläufiger Bericht der Studiendelegation der Juristen, BAB, DP1 VA Nr. 175.

65 Siehe Benjamin an Geyer, 27. 5. 1952, BAB, DP1 VA Nr. 5597.

66 Vorläufiger Bericht der Studiendelegation der Juristen, BAB, DP1 VA Nr. 175; vgl. auch Kladde Benjamins, BAB, DP1 VA Nr. 7675, Bl. $173 \mathrm{f}$.

67 Das Rückreisedatum läßt sich indirekt aus Benjamins Danksagungen anläßlich der Feier zu ihrem 85. Geburtstag erschließen: siehe Benjamin, Worte des Dankes, S. 64. 
schließlich doch nicht teil68 - bewegte sich ausschließlich in Moskau und seiner unmittelbaren Umgebung, erhielt dort aber Einblicke in Gerichte, Staatsanwaltschaften, Justizverwaltung und Ausbildungsstätten auf allen Ebenen. Der Schwerpunkt lag dabei auf den Gerichten und Staatsanwaltschaften, die sowohl in einem ländlichen als auch in einem städtischen Moskauer Rayon besichtigt wurden. Die Delegation besichtigte zudem das für das Gebiet Moskau zuständige Gericht, die dort tätige Staatsanwaltschaft sowie die Gebietsjustizverwaltung. Auf Republiksund Unionsebene (RSFSR und UdSSR) standen jeweils das Oberste Gericht, die Oberste Staatsanwaltschaft und das Justizministerium auf dem Programm. Ebenfalls besucht wurden das Notariatsbüro sowie das Anwaltskollegium der Stadt Moskau. Der Ausbildungs- und Wissenschaftsbetrieb wurde anhand einer Zweijahresschule für juristische Bildung, des juristischen Instituts (einer zentralen Vierjahresschule) und der juristischen Abteilung der Akademie der Wissenschaften studiert ${ }^{69}$. Auf jeder Station ihres Besuchs informierten die sowjetischen Genossen zunächst über Struktur und Arbeit der jeweiligen Behörde, gewährten Einblicke in Arbeitspläne und Gerichtsakten und ließen die SED-Juristen auch an Gerichtsverhandlungen teilnehmen. Diese machten sich eifrig Notizen, die täglich im Kollektiv kontrolliert wurden; jede Arbeitsgruppe hielt die so gewonnenen Ergebnisse direkt in maschinenschriftlicher Form fest ${ }^{70}$. All dies diente dem Ziel einer umfassenden, lückenlosen Bestandsaufnahme, um eine Übertragung zentraler Elemente des sowjetischen Justizwesens auf die DDR zu ermöglichen.

Nach Rückkehr der Studiendelegation nach Ost-Berlin wurde für die Parteispitze zunächst ein ausführlicher „Vorläufiger Bericht" erstellt, der die Besonderheiten der sowjetischen Gerichtsorganisation, Justizverwaltung und Staatsanwaltschaft sowie des Ausbildungswesens darstellte und dabei bisweilen auf die Unterschiede zur DDR-Praxis einging71. Interessanter ist eine „Auswertung“ des Reiseberichts für die DDR-Justiz von Benjamin, Artzt und Gerats, die am 26. Juni an den Leiter des SED-Justizsektors geschickt wurde ${ }^{72}$. Die Verfasser empfahlen, das sowjetische System sowohl im Hinblick auf seine Organisation als auch auf seine Verfahrensweisen weitgehend zu kopieren ${ }^{73}$. Bisweilen wurde freilich von einer Übernahme abgeraten: So hielten die Verfasser des Berichts beispielsweise die Wahl der Richter unmittelbar durch die Bevölkerung "noch nicht für möglich“. Auch dabei folgten sie dem Ratschlag eines sowjetischen Genossen, der der Delegation in diesem Zusammenhang erläutert hatte, daß man eine solche Wahl erst durchführen könne, „wenn man eine starke Partei hat“. Aus einem ähnlichen Grund sollte der erste Senat des Obersten Gerichts der DDR - anders als in der Sowjetunion - keine Schöffen hinzuziehen, „da die Auswahl der Schöffen nach

68 Vgl. Benjamin an MdJ, 24. 6. 1952, BAB, DP1 VA Nr. 6985.

69 Zusammenfassender Bericht über die Ergebnisse der Studiendelegation der Juristen, 22. 9. 1952, SAPMO, DY 30 IV 2/13/448, Bl. 239-243, hier 240.

70 Vorläufiger Bericht der Studiendelegation der Juristen, BAB, DP1 VA Nr. 175.

71 Ebenda.

72 Benjamin an Spank, 26.6. 1952, SAPMO, DY 30 IV 2/13/448, Bl. 1. Auf Wunsch Benjamins wurde der Bericht am 28. 6. 1952 auch an Ulbricht weitergeleitet, ebenda, Bl. 91.

73 Zweiter Bericht der Studiendelegation der Juristen. Auswertung der tatsächlichen Feststellungen aus dem 1. Bericht, ebenda, Bl. 200-238. Auch in: BAB, DP1 VA Nr. 175 (daraus auch die folgenden Zitate). 
dem Blockprinzip für die zur Zeit noch notwendige Art der Tätigkeit des ersten Senats nicht geeignet erscheint". Vor allem den bürgerlichen Parteien angehörende Schöffen konnten, so die dahinter stehende Befürchtung, die Ausschaltung politischer Gegner in Prozessen vor dem ersten Senat möglicherweise gefährden. Zur Einstimmung der Justizangehörigen der DDR auf die bevorstehenden Änderungen veröffentlichte Benjamin im August-Heft der "Neuen Justiz" unter dem Titel „Deutsche Juristen in der Sowjetunion“ einen Artikel über die meisten besichtigten Einrichtungen, an dessen Ende sie etwas verklausuliert auf die Vorbildfunktion der sowjetischen Justizorgane hinwies: „Wenn wir jetzt im Rahmen unserer Verwaltung auch zu einem Neuaufbau unserer Justiz kommen, werden uns manche Grundgedanken der sowjetischen Gerichtsorganisation helfen, die unserer jetzigen Lage entsprechende Form für unsere Justizorgane zu finden." ${ }^{74}$ Bereits zuvor hatten alle Delegationsmitglieder vor ihren Betriebsgruppen über die Reise berichtet; seit Ende Juli traten sie auch im Rahmen der sogenannten „Breitenschulung“ der Landgerichte auf ${ }^{75}$. Nach einer Anweisung Benjamins hatten sie bei dieser Gelegenheit "bei allen Mitarbeitern der Justiz Verständnis und Begeisterung für den Umbau, der jetzt bei uns in der Justiz vorgenommen wird, zu wecken "76. Insgesamt traten die Delegationsmitglieder in rund 40 Veranstaltungen auf, die von durchschnittlich etwa 100 Teilnehmern besucht wurden ${ }^{77}$. Ihren Berichten zufolge waren die Schulungen fast durchweg erfolgreich und trafen auf aufgeschlossene Justizfunktionäre. Auch wenn man einbezieht, daß die Schreiben geschönt waren, so lassen sich doch zwei Gründe anführen, die für diese Sicht sprechen: Einmal wurden den Justizangehörigen die anstehenden Veränderungen dadurch schmackhaft gemacht, daß die Angelegenheiten der freiwilligen Gerichtsbarkeit aus der Justiz ausgegliedert werden sollten, wovon sich viele offensichtlich eine Entlastung erhofften. Hinzu kam, daß mit der Schaffung der Bezirke am 23. Juli jedem klar war, daß auch bei dem auf die Länder zugeschnittenen Justizwesen organisatorische Veränderungen anstanden, die wahrscheinlich mit Versetzungen und Entlassungen verbunden sein würden. Nach einem Bericht von Artzt überlagerten diese persönlichen Sorgen „die Aufnahmebereitschaft für grundsätzliche Fragen"78; eine derartige Atmosphäre ließ jedoch auch Kritik kaum aufkommen ${ }^{79}$.

Die Sowjetisierung des DDR-Justizwesens machte nach der Moskaureise der SED-Juristen rasche Fortschritte. Wie bereits andernorts ausgeführt, betraf dies

74 Benjamin, Deutsche Juristen, S. 348.

75 Zur Planung dieser Aktivitäten siehe das Papier „Auswertung der Arbeit der Delegation der Juristen", 21. 6. 1952, sowie Benajmin an MdJ, 24. 6. 1952, und MdJ (Toeplitz) an Benjamin, 3. 7. 1952, BAB, DP1 VA Nr. 6985.

76 Benjamin an Ranke, 23. 7. 1952, BAB, DP1 VA Nr. 6983; gleichlautende Schreiben auch an die anderen Delegationsmitglieder in: BAB, DP1 VA Nr. 6985.

77 Zusammenfassender Bericht über die Ergebnisse der Studiendelegation der Juristen, 22. 9. 1952, SAPMO, DY 30 IV 2/13/448, Bl. 241.

78 Vgl. Ranke an Benjamin, 28. 7., 6. 8. 1952, BAB, DP1 VA Nr. 6983; Schmuhl an Benjamin, 1. 7. 1952, Schultz an Benjamin, 3.7. 1952, Utech an Benjamin, 4. 7. 1952, Artzt an Benjamin, 24.7. 1952, (dort auch das Zitat), BAB, DP1 VA Nr. 6985.

79 Benjamin vermerkte in ihrem Bericht an die Abteilung Schulung des MdJ vom 21. 8. 1952 über die Breitenschulung in Leipzig allerdings einige kritische Töne, die sich unter anderem auf die Erklärungen einiger Justizangestellten bezogen, „sie wollten nicht im Strafrecht arbeiten“, ebenda. 
unter anderem die Struktur des MdJ, das eine Kaderabteilung und ein Kollegium erhielt, die regionale Justizverwaltung mit ihren nun errichteten Justizverwaltungsstellen, Struktur und Kompetenzen des Obersten Gerichts ${ }^{80}$, die Erstellung einer Disziplinarordnung und die 1953 einsetzende sogenannte „Kollektivierung“ der Rechtsanwaltschaft ${ }^{81}$.

\section{Der Wandel der Gerichtsverfassung}

Bei der neuen Gerichtsorganisation, wie sie sich im GVG vom 2. Oktober 1952 niederschlug, lassen sich die Anpassungen an das sowjetische Vorbild deutlich nachvollziehen, wenngleich die Überlegungen zur Reform der Gerichtsverfassung in der SBZ/DDR bis auf Eugen Schiffer zurückgingen. Dieser hatte im März 1948 auf sowjetische Anweisung hin 82 bei der SMAD-Rechtsabteilung ein Memorandum „über eine durchgreifende Neuorganisation des deutschen Gerichtswesens" eingereicht, das drei Grundelemente enthielt: Schaffung eines einheitlichen Eingangsgerichts, dreistufiger Gerichtsaufbau (Bezirksgericht, Obergericht, Reichsgericht) und möglichst weitgehende Deckung der Gerichts- und Verwaltungsbezirke ${ }^{83}$. Ebenfalls auf Karassjows Wunsch ${ }^{84}$ entwickelte Schiffer Gedanken zu einer weiteren Neuordnung des GVG, die sich vor allem um die Richterpersönlichkeit drehten. Bei den Berufsrichtern wollte Schiffer neben den akademisch vorgebildeten Juristen und den Absolventen der Volksrichterschulen sogenannte „Koryphäenrichter" einstellen, die kein juristisches Studium absolviert, sich aber im öffentlichen Leben bewährt hatten ${ }^{85}$. Der DJV-Präsident beantragte eine Länderkonferenz in dieser Angelegenheit, was jedoch von der SMADRechtsabteilung nach Rücksprache mit der SED-Führung abgelehnt wurde ${ }^{86}$. Die SED-Justizabteilung sprach sich explizit gegen das Reformvorhaben Schiffers aus, das einiges von dem vorwegnahm, was 1952 in der DDR eingeführt werden sollte. Die SED-Juristen argumentierten, daß eine derartige Neuregelung die Rechtseinheit in Deutschland gefährde und daher inopportun sei; zudem bemängelten sie die bei dem Vorschlag Schiffers erkennbare Tendenz zur „Errichtung eines Justizstaates, wobei dem Justizapparat durch eine besonders straffe und verkleinerte Organisation eine Sonderstellung eingeräumt werden soll“. In diesem Zusammenhang bezeichneten sie auch die Aufhebung der Amtsgerichte als „eine anti-

80 Vgl. dazu Kap. B.II.3, B.III.3, B.VII.3.

81 Vgl. dazu Lorenz, Disziplinarrecht, S. 382-386; ders., Rechtsanwaltschaft in der DDR, S. 97-220. Die für den Entscheidungsprozeß der Jahre 1952/53 zentrale Moskaureise erwähnt Lorenz freilich nicht.

82 Siehe Aktenvermerk Stackelbergs über den Besuch Dozenkos bei Schiffer am 26. 2. 1948, 26. 2. 1948, BAB, DP1 VA Nr. 11, Bl. 128.

83 Schiffer an Chef der SMAD-Rechtsabteilung, 9. 3. 1948, BAB, DP1 VA Nr. 7814, Bl. 1-10. Das Memorandum wurde Karassjow am 10.3. 1948 übergeben: siehe Vermerk Lange, 10. 3. 1948, BAB, DP1 VA Nr. 7164.

84 Ebenda.

85 Vermerk von Rosenthal-Pelldram und Guski zur Frage eines neuen GVG, 25. 3. 1948; Vermerk Schiffers, 14. 4. 1948, ebenda.

86 Vermerk Walters über ein Telefonat mit Jakupow, 26. 4. 1948, BAB, DP1 VA Nr. 780, Bl. 16; Vermerk über eine Unterredung mit Karassjow und Jakupow, 26. 4. 1948, ebenda, Bl. 17. Protokoll der Zentralsekretariatssitzung, 26. 4. 1948, SAPMO, DY 30 J IV 2/2.1/193, TOP 22. 
demokratische Maßnahme" ${ }^{\text {87 }}$. Dies ist insofern bemerkenswert, als auch Schiffer mit seinen Vorschlägen "die Errichtung einer demokratischen Rechtsordnung“ fördern wollte: Ihm ging es dabei vor allem um die Übersichtlichkeit des Gerichtsaufbaus sowie darum, dem Rechtsuchenden die Anrufung des zuständigen Gerichts zu erleichtern. Der ,Konservativismus' der SED in dieser Frage hing vor allem damit zusammen, daß die Umsetzung von Schiffers Vorschlag die Auflösung von 242 der bestehenden 438 Amtsgerichte bedeutet hätte ${ }^{88}$. Und an den Amtsgerichten waren damals noch die meisten Richter mit einem SED-Parteibuch tätig. Solange also der personelle Parteieinfluß in der Justiz so gering war, wollte man auf seiten der SED lieber das alte Justizsystem benutzen als dessen Änderung im Sinne Schiffers befördern.

Als Anfang 1949 in der DJV „auf Wunsch der SMAD-Rechtsabteilung“89 die Arbeiten an dem GVG wiederaufgenommen wurden, griff Nathan zumindest hinsichtlich der Gerichtsorganisation auf die Planungen Schiffers zurück; als Richter wollte er freilich nur akademisch oder in den Volksrichterkursen ausgebildete Personen akzeptieren ${ }^{90}$. Vereinfachung und Rationalisierung der Gerichtsorganisation lagen durchaus auch im Sinne der SED, sobald durch die Besetzung der zentralen Positionen garantiert war, daß der Justiz nicht jene unabhängige Stellung zukam, die Schiffer angestrebt hatte. Neu im Entwurf Nathans war die Einführung der Schöffenwahl durch die Kreistage und Stadtverordnetenversammlungen: Damit schrieb er jedoch nur fest, was bereits durch die Schöffenwahlgesetze in mehreren Ländern eingeführt worden war ${ }^{91}$. Obwohl die SMADRechtsabteilung auf einer fristgemäßen Einreichung des Entwurfs zum 3. März 1949 bestand $^{92}$, blieb eine Stellungnahme aus Karlshorst aus, so daß vorerst an dem noch gesamtdeutsch geltenden GVG festgehalten wurde. Dessen Bestimmungen wurden in der folgenden Zeit vor allem durch einzelne Normativakte modifiziert: Dazu zählte unter anderem die Verordnung über die Besetzung der Strafkammern vom 6. August 1949, derzufolge die großen Strafkammern in der Hauptverhandlung in der Besetzung von zwei Richtern und drei Schöffen zu entscheiden hatten, was eine Abweichung von $₫ 76$, Abs. 2 des GVG bedeutete ${ }^{93}$. Eine weitergehende Änderung bildete die Gründung des Obersten Gerichts und der Obersten Staatsanwaltschaft. Auch dieser Akt stellte jedoch, wie Fechner am 7. Dezember 1949 in der Volkskammer ausführte, erst den Anfang der „Neuorganisation unseren [sic] Justizwesens“ dar, und er fuhr fort: „Es wird notwendig

87 Stellungnahme der Justizabteilung zu der von Schiffer vorgeschlagenen Neuordnung des GVG, gez. Schäfermeyer, 29. 4. 1948, BAB, DP1 VA Nr. 7844, Bl. 20-24.

88 Schiffer an Chef der SMAD-Rechtsabteilung, 9.3. 1948, BAB, DP1 VA Nr. 7814, Bl. 1 (Zitat), 4.

89 Arbeitsprogramm für die Abteilung III 5 für das 1. Halbjahr 1949, BAB, DP1 VA Nr. 289, Bl. 1518 , hier 16.

90 Grundsätze für die Aufstellung des Entwurfs eines GVG, am 3.2.1949 Karassjow vorgetragen; I. Entwurf Gerichtsverfassungsgesetz, am 2. 3. 1949 der SMAD-Rechtsabteilung übermittelt, BAB, DP1 VA Nr. 7164.

91 Vgl. dazu Görner, Schöffen und Volksgericht, S. 43. Die Schöffenwahlgesetze beruhten auf einem in der DJV ausgearbeiteten, mit der SED-Justizabteilung beratenen und von der SMAD genehmigten Entwurf: siehe dazu Neumann an Fechner, 17.8. 1948, BAB, DP1 VA Nr. 7844, Bl. 1-14; Grundsätze für die Aufstellung des Entwurfs eines GVG, BAB, DP1 VA Nr. 7164.

92 Vermerk betr. Unterredung Fechners mit Karassjow, 25. 2. 1949, ebenda.

${ }_{93}$ ZVOBl. 1949, S. 614; zur Vorgeschichte der Verordnung siehe Kap. B.VIII.3. 
sein, in absehbarer Zeit den Entwurf eines Gerichtsverfassungsgesetzes vorzulegen, das die gesamte heutige Gerichtsorganisation umgestalten und in Einklang mit den Erfordernissen unserer staatlichen Entwicklung bringen soll." ${ }^{49}$

Eine Neugestaltung des GVG blieb zunächst aus deutschlandpolitischen Gründen noch aus. Dies hinderte die Sowjetunion jedoch nicht, in die Gerichtsorganisation einzugreifen, wenn ihr dies, wie im Zusammenhang mit dem Uranbergbau in Sachsen und Thüringen, erforderlich schien. Auf die Schaffung einer gesetzlichen Grundlage wurde anscheinend bewußt verzichtet; statt dessen ordnete der sächsische Justizminister am 26. Februar 1949 justizintern an, eine Abteilung für Strafsachen des Amtsgerichts Chemnitz in Siegmar-Schönau zu bilden, die ausschließlich für Straftaten deutscher Angestellter und Arbeiter der Wismut AG sowie für alle Straftaten, in denen die Wismut die Verletzte war, zuständig sein sollte ${ }^{95}$. Die Abteilungen für Wismut-Strafsachen wurden in den nächsten Jahren ausgebaut; im Oktober 1950 errichtete auch das Landgericht Chemnitz auf Anweisung des sächsischen Justizministeriums eine entprechende Strafkammer ${ }^{96}$. Ab April 1952, als eine solche Kammer auch beim Landgericht Gera errichtet wurde ${ }^{97}$, firmierten diese als „Bergbau-Abteilungen“. Wie Fechner der Zentralen Stellenplaninspektion erläuterte, waren sie „auf Wunsch der Freunde errichtet“ worden, formell den Landgerichten angegliedert, in ihrer ganzen Arbeit aber selbständig ${ }^{98}$. Faktisch waren damit trotz des im GVG und in der DDR-Verfassung festgeschriebenen Verbots Sondergerichte errichtet worden, auch wenn es sich formell nur um Sonderstrafkammern handelte. Als weiterer Eingriff in das GVG muß die eigenwillige Auslegung des auch in der DDR-Verfassung verankerten Grundsatzes „Kein Bürger darf seinem gesetzlichen Richter entzogen werden“ durch das Oberste Gericht gewertet werden, das am 7. Juni 1951 entschied: „Das Gebot, niemandem seinem gesetzlichen Richter zu entziehen, will verhindern, daß eine Sache, die zur Zuständigkeit der ordentlichen Gerichte gehört, an eine andere Stelle oder eine Verwaltungsbehörde überwiesen wird. Ist aber eine Sache bei dem dafür örtlich und sachlich zuständigen Gericht anhängig, so ist der Bürger seinem gesetzlichen Richter nicht entzogen, wenn der Prozeß von einem Richter, der dem Gericht zur Zeit der Verhandlung angehört, entschieden wird.“ Dies legalisierte die Praxis, Beschuldigte von Richtern aburteilen zu lassen, die zwar nicht zuständig, aber politisch zuverlässig waren ${ }^{99}$.

Trotz dieser Eingriffe in die Gerichtsorganisation blieb das GVG bis Oktober 1952 auch für die DDR gültig. Erst nach dem Justizbeschluß begannen in der damit befaßten Unterkommission unter Benjamins Leitung im März 1952 ernsthafte Erörterungen zu seiner Umgestaltung auf der Grundlage eines Entwurfs des MdJ, des sowjetischen GVG vom 16. August 1938 und eines Lehrbuchs von

94 Provisorische Volkskammer, Sitzungen, S. 71; vgl. Kap. B.VII.1.

95 Anordnung des Justizministeriums Sachsen, 26. 2. 1949, BAB, DP1 VA Nr. 6542, Bl. 269; vgl. auch Kaden, Kriminalität, S. 154.

96 Präsidialbeschluß des Landgerichts Chemnitz, 16. 10. 1950, BAB, DP1 VA Nr. 6542, Bl. 272.

97 Betr.: Einrichtung einer Bergbau-Abteilung beim Landgericht Gera, BAB, DP1 VA Nr. 6584, Bl. 320; vgl. Weber, Justiz und Diktatur, S. $346 \mathrm{f}$..

$98 \mathrm{MdJ}$ an Zentrale Stellenplaninspektion bei der ZKStK, 31.10. 1952, BAB, DP1 VA Nr. 7842, Bl. $403 \mathrm{f}$.

99 Entscheidungen des Obersten Gerichts, Bd. 2, S. 188; vgl. Weber, Justiz und Diktatur, S. 205. 
D.S. Karew ${ }^{100}$. Das erste Ergebnis waren eine Reihe von „Thesen zum Gerichtsverfassungsgesetz“, die von der Grundkommission am 28. März genehmigt und anschließend mit Jakupow besprochen wurden ${ }^{101}$. Die Orientierung am sowjetischen Vorbild läßt sich bereits teilweise an den „Thesen“ nachweisen, so etwa bei den Ausführungen zum Obersten Gericht. Was die Gerichtsstruktur angeht, bestanden keine Differenzen zwischen den bereits 1948/49 in der DJV entstandenen Überlegungen und den Verhältnissen in der Sowjetunion: Die Unterkommission betonte die Notwendigkeit, die Gerichtsstruktur „in Übereinstimmung zu bringen mit der Verwaltungsstruktur", so daß Gerichte auf Kreis-, Länder- und Republiksebene einzurichten waren. Nach der Reise in die Sowjetunion sahen Benjamin, Artzt und Gerats durch den Aufbau des sowjetischen Gerichtssystems mit Volksgericht, Gebietsgericht und Gericht der Republik „die Richtigkeit der von uns vorgesehenen neuen Gerichtsstruktur" bestätigt ${ }^{102}$. Bestärkt fühlten sich die Genossen zudem in ihrem Vorhaben, die Schöffen nicht mehr durch die kommunalen Vertretungen, sondern direkt durch das Volk wählen zu lassen. Geklärt wurden ebenfalls Detailfragen wie die Besetzung der Strafkammern: In den „Thesen" war noch zwischen der "großen" und der „kleinen“ Strafkammer differenziert worden, während man nunmehr, wie in der Sowjetunion ${ }^{103}$, einheitlich von einer Strafkammer in der Besetzung eines Berufsrichters und zwei Schöffen ausging. Auch eine weitere Frage wurde prinzipiell geklärt: Die Angelegenheiten der freiwilligen Gerichtsbarkeit sollten, wie in der Sowjetunion auch, aus der Justiz ausgegliedert werden.

Die Ausarbeitung des GVG und der anderen Justizgesetze übernahm eine formell mit Regierungsbeschluß vom 12. Juni 1952 eingesetzte Kommission ${ }^{104}$, die elf Tage später erstmals zusammentrat. Benjamin erhielt den Vorsitz sowohl über die Gesamtkommission als auch über die Unterkommission für das GVG. Da die Auflösung der Länder und die Neugliederung der DDR in Bezirke bereits feststand, drängte die Zeit für die Reorganisation des Gerichtswesens. Daher wurde in der ersten Sitzung der Gesamtkommission am 23. Juni festgelegt, daß die - faktisch im Frühjahr von einer Politbüro-Kommission begonnenen - Arbeiten am GVG bis Ende Juli zu beenden waren ${ }^{105}$. Auch in diesem Stadium des, Gesetzgebungsprozesses ${ }^{6}$ beteiligten sich die SKK-Vertreter. Titow und Jakupow hatten sich bereits vor dem 23. Juni nach eingehenden Beratungen mit der unmittelbaren Wahl der Schöffen einverstanden erklärt und „die Loslösung der freiwilligen Gerichtsbarkeit aus der Justiz dringend vorgeschlagen“. Beide bestanden aber darauf, daß diese Fragen „letzten Endes von der Partei entschieden werden müssen“.

100 Arbeitsplan der Unterkommission GVG, BAB, DP1 VA Nr. 8070. Bei dem sowjetischen Lehrbuch handelte es sich um: Karew, Sowjetische Justiz.

101 Thesen zum Gerichtsverfassungsgesetz; Bemerkungen zu den am 28. 3. 1952 angenommenen Thesen zum GVG, ebenda.

102 Auswertung der Ergebnisse [der Reise in die Sowjetunion], BAB, DP1 VA Nr. 175.

103 Siehe dazu Karew, Sowjetische Justiz, S. 48.

104 Protokoll der Regierungssitzung, 12. 6. 1952, BAB, DC 20 I/3 Nr. 112, TOP 12. Zu dem Beschluß siehe auch N[athan], Eine neue Etappe, in: NJ 6 (1952), S. 289. Vorangegangen war der Sekretariatsbeschluß vom 21. 5. 1952: siehe oben, Anm. 58.

105 Protokoll der 1. Tagung der Gesetzgebungskommission, 23.6. 1952, BAB, DP1 SE Nr. 3360, Bl. 4-6; Vorläufiger Schlußbericht über die bisherige Tätigkeit der Regierungskommission, ebenda, Bl. 89-91, hier 89 . 
Die SKK-Justizabteilung wollte offensichtlich den formal ,richtigen' Weg gehen und weitreichende Festlegungen nicht hinter dem Rücken des faktischen Souveräns in der DDR treffen. Benjamin schickte tags darauf ein Schreiben an die Abteilung Staatliche Verwaltung und ein weiteres an Polak, der zu den Beratungen über das GVG hinzugezogen wurde und dessen engen Kontakt zu Ulbricht sie nutzen wollte, um „gegebenenfalls“ bei diesem eine Entscheidung herbeizuführen ${ }^{106}$. Die Genossen im zentralen Parteiapparat ließen sich nicht lange bitten und ermöglichten mit ihrer Zustimmung die zügige Fortsetzung der Beratungen, so daß die Endfassung des GVG-Entwurfs am 14. Juli von der Gesamtkommission diskutiert werden konnte ${ }^{107}$. Unmittelbar danach wurde der Gesetzentwurf an die SKK und die Abteilung Staatliche Verwaltung übersandt. Die alles entscheidende Antwort aus Karlshorst erhielt Benjamin erst am 8. August. Die Verzögerung war darauf zurückzuführen, daß dort „dem Gesetz eine besondere Wichtigkeit und grundlegende Bedeutung" beigemessen wurde, was einen Vortrag nicht nur vor der SKK-Spitze, sondern auch die Unterrichtung des stellvertretenden sowjetischen Außenministers Wyschinski nach sich zog. Die sowjetischen Stellen nahmen jedoch nur geringfügige Änderungen vor, so daß Benjamin den Entwurf am 13. August an den Leiter des Justizsektors, Richard Spank, zur Beschlußfassung im Politbüro weiterleiten konnte ${ }^{108}$. Dort wurde das Gesetz am 26. August beschlossen; zur Überführung der freiwilligen Gerichtsbarkeit auf andere staatliche Organe beauftragte das SED-Führungsgremium den Justizminister mit der Ausarbeitung entsprechender Überleitungsbestimmungen und Richtlinien ${ }^{109}$. Die DDR-Regierung stimmte dem GVG schließlich am 11. September, die Volkskammer am 2. Oktober $1952 \mathrm{zu}^{110}$.

\section{Der Wandel des Strafprozeßrechts}

Am selben Tag verabschiedete die Volkskammer ebenfalls eine neue Strafprozeßordnung. Damit vollzog die DDR einen Bruch mit der deutschen Tradition, da auf diese Weise die Strafprozeßordnung von 1877 endgültig beseitigt wurde. 1945 war, in Übereinstimmung mit den einschlägigen Normen des Alliierten Kontrollrats, an der Geltung der StPO auch für die SBZ kein Zweifel gelassen worden; grundsätzlich sollte von der Fassung vom Januar 1933 ausgegangen werden ${ }^{111}$. Dieser Grundsatz ließ sich jedoch kaum einhalten, da keineswegs alle Änderungen und Ergänzungen aus der Zeit des Dritten Reiches auf nationalsozialistisches Gedankengut zurückgingen, sondern oftmals nur vollendeten, was bereits vor 1933 geplant worden war und sich als durchaus praktikabel erwiesen hatte. In der

106 Benjamin an Abteilung Staatliche Verwaltung, 24.6. 1952, ebenda, Bl. 111-113; Benjamin an Polak, 24. 6. 1952, ebenda, Bl. 109.

107 Vorläufiger Schlußbericht über die bisherige Tätigkeit der Regierungskommission, ebenda, Bl. 89.

108 Benjamin an Spank, 13. 8. 1952, BAB, DP1 VA Nr. 8070.

109 Protokoll der Politbürositzung, 26. 8. 1952, SAPMO, DY 30 J IV 2/2/228, TOP 4.

110 Protokoll der Regierungssitzung, 11.9. 1952, BAB, DC 20 I/3, Nr. 131, TOP 3; der Abstimmungstermin über das Gesetz in der Volkskammer wurde hinausgezögert, weil man das GVG dort zusammen mit der StPO verabschieden wollte: siehe Benjamin an Geyer, 1. 9. 1952, ebenda, Bl. 104. Das GVG in: GBI. 1952, S. 996-1029.

111 Vgl. Luther, Strafprozeßrecht, S. 345. 
SBZ mußte demnach festgelegt werden, welche Novellen der StPO beizubehalten waren und welche nicht. Nachdem dieses Thema erstmals auf der Länderkonferenz vom 13. Dezember 1946 erörtert, eine Entscheidung aber auf Anregung Jakupows verschoben worden war, verkündete Schiffer auf der Länderkonferenz am 11./12. April 1947 als Faustregel, „daß im Zweifel der Rechtszustand vor 1933 zugrundegelegt wird, und nur da, wo unzweifelhaft nicht nazistisches Gedankengut zugrundeliegt und nur da, wo ein gewichtiges Bedürfnis vorliegt, [...] auf Gesetze aus der Nazizeit" zurückzugreifen sei"112. Da auch diese Regelung nicht konsensfähig war, der brandenburgische Justizminister sich dagegen sträubte ${ }^{113}$ und das zur Anwendung kommende Verfahrensrecht weiterhin uneinheitlich blieb, wurde am 12. Oktober 1948 eine Konferenz von Vertretern der Landesjustizministerien in die DJV einberufen, die über die StPO zu befinden hatte ${ }^{114}$. Sämtliche nach 1933 vorgenommenen Änderungen wurden überprüft, um eine für die SBZ einheitliche Textausgabe vorzubereiten. Aufgrund der vorangeschrittenen Zentralisierung der Justizverwaltung konnte ein Konsens erzielt werden, so daß 1949 erstmals eine nur für die SBZ gültige Strafprozeßordnung erschien. Ein Vergleich mit der im Westen angewandten Fassung ergab sehr weitgehende Übereinstimmungen. Die Konferenz hatte sich anscheinend an die von Schiffer 1947 formulierte Richtschnur gehalten, da man grundsätzlich auf die Fassung von $1933 \mathrm{zu}$ rückgriff und aus den späteren Novellen nur die Vorschriften übernahm, „die sich sowohl praktisch bewährt hatten als auch unberührt von spezifisch nationalsozialistischen Gedanken schienen"115.

Trotz dieser grundsätzlichen Kontinuität scheute sich die Besatzungsmacht auch vor 1949 nicht, die rechtsstaatlichen Garantien des Strafprozeßrechts an einigen entscheidenden Stellen auszuhebeln. Dazu zählen die Verordnung über das Verfahren in Wirtschaftsstrafsachen vom 21. Oktober 1947, die Kassationsgesetze der Länder ${ }^{116}$ und insbesondere die Vorschriften für das Untersuchungsverfahren der 201-Prozesse. Dies hatte vor allem für die Strafverfolgung in politischen Sachen zur Folge, daß das MfS weitgehend in eigener Regie ermittelte und gegen die Strafprozeßordnung verstieß ${ }^{117}$. Nach der Staatsgründung wurden Eingriffe ins Verfahrensrecht auch ohne erkennbare sowjetische Intervention von den zentralen Justizorganen der DDR vorgenommen. So erschwerte das MdJ mit Rundverfügung vom 29. Juni 1951 den Verteidigern die Einsichtnahme in die Prozeßakten: Obwohl die Strafprozeßordnung in $\$ 147$ Abs. 4 die Möglichkeit vorsah, die Akten dem Verteidiger mitzugeben, war Akteneinsicht von nun an nur noch in Gegenwart eines Richters oder eines von diesem bestimmten Angestellten möglich; außerdem durfte der Anwalt zu diesem Zweck nicht einen Mitarbeiter schicken,

112 Stenographisches Protokoll der Länderkonferenz, 13.12. 1946, BAB, DP1 VA Nr. 6957, hier Bl. 222; Stenographische Konferenz der Länderkonferenz, 11./12.4. 1946, BAB, DP1 VA Nr. 6958, hier Bl. 71.

${ }^{113}$ Mit Rundverfügung vom 28.6. 1947 wurden die Ausnahmen von der von Schiffer aufgestellten "Faustregel“" spezifiziert; der brandenburgische Justizminister wandte sich am 12.7. 1947 unter Berufung auf die Rechtsprechung des Oberlandesgerichts Potsdam gegen eine solche generelle Regelung, BAB, DP1 VA Nr. 6348.

$114 \mathrm{Vgl}$. Weiß, Einheitliches Strafverfahrensrecht, S. $215 \mathrm{f}$.

115 Siehe insgesamt v. Bargen, Strafprozeßordnung in der SBZ, passim, Zitat S. 50.

116 Vgl. Kap. A.V.1 und 2.

117 Vgl. Kap. B.VI.2 und 4. 
sondern mußte selbst erscheinen 118 . Handelte es sich dabei noch um eine Schikane, so bedeutete die Feststellung Benjamins auf der Tagung der Oberlandesgerichtspräsidenten im März 1951, daß die "Staatsstruktur“ der DDR es gebiete, den Protokollen der ZKK und des MfS den gleichen Beweiswert wie richterlichen Protokollen zuzuerkennen, nichts anderes als eine Aufforderung, die Strafprozeßordnung in diesem wesentlichen Punkt zu mißachten ${ }^{119}$.

Als die StPO im März und April 1952 auf Veranlassung des Politbüros einer systematischen, kritischen Überprüfung unterzogen wurde, war sie bereits an zahlreichen Stellen ausgehöhlt worden. Die zuständige Unterkommission erhielt den Auftrag, die damalige Rechtslage und strafprozessuale Praxis vor dem Hintergrund „der Gesetze der Sowjetunion und der Volksdemokratien“ sorgfältig zu untersuchen und zu kritisieren ${ }^{120}$. Zunächst wollte sie sich „mit einer neuen Fassung des bisherigen Gesetzes" begnügen ${ }^{121}$. Nach dem sowjetischen Memorandum vom Mai 1952 reichte dies jedoch nicht mehr aus. Die Gesetzgebungskommission der Regierung, die nach Rückkehr der SED-Delegation aus der Sowjetunion aktiv wurde, beschloß, bis Ende August die Arbeiten zu beenden, und konnte diesen Termin auch einhalten: Nach fünf Kommissions- und fünf Unterkommissionssitzungen wurde am 18. August abschließend über die StPO bera$\operatorname{ten}^{122}$.

Trotz der weitgehenden Übernahme sowjetischer strafprozessualer Praktiken und der Abschaffung traditioneller deutscher Rechtsinstitute wie der Revision wurde in Einzelfällen das sowjetische Vorbild nicht kopiert. So empfahlen Benjamin, Artzt und Gerats zwar, in Anlehnung an die Praxis des Obersten Gerichts in der Sowjetunion, die nach dem Recht der DDR noch bestehende einjährige Ausschlußfrist zu beseitigen; in der Strafprozeßordnung vom 2. Oktober 1952 wurde jedoch daran festgehalten ${ }^{123}$. Die Ausarbeitung eines neuen Strafverfahrensrechts wurde vor allem dazu genutzt, um die zahlreichen, oftmals auf sowjetische Anweisungen zurückzuführenden Durchbrechungen der alten StPO zu ,legalisieren'. Zwar war schon in der StPO von 1949 die richterliche Voruntersuchung „zu einer strafverfahrensrechtlichen Rarität" geworden ${ }^{124}$; nun wurde sie jedoch, unter eindeutiger Anlehnung an die Praxis der 201-Verfahren, abgeschafft und das Untersuchungsverfahren völlig vom Gerichtsverfahren abgekoppelt. Es stand formell unter Aufsicht des Staatsanwalts. Die Eröffnung des Ermittlungsverfahrens lag jedoch nicht allein in seiner Macht; nach $\$ 106$ konnte auch der Leiter des Un-

118 Rundverfügung Nr. 93/51, 29.6. 1951, BAB, DP1 VA Nr. 5930; vgl. dazu auch die Aktennotiz Böhmes, 9. 5. 1951, ebenda.

119 Siehe Benjamin, Grundsätzliches zur Methode und zum Inhalt der Rechtsprechung, S. 154; vgl. Kap. B.VII.5.

120 Protokoll über die Sitzung der Unterkommission Strafprozeßordnung, 15. 3. 1952, BAB, DP1 VA Nr. 8071.

121 So das Fazit der in der Sitzung der Grundkommission vom 28. 3. 1952 genehmigten Thesen zur StPO, ebenda.

122 Vorläufiger Schlußbericht über die bisherige Tätigkeit der Regierungskommission, BAB, DP1 SE Nr. 3360, B1. 89 f.

123 Auswertung der Ergebnisse [der Reise in die Sowjetunion], BAB, DP1 VA Nr. 175; StPO $\$ 303$, Abs. 1. Bereits Westen, Zur Rechtsentwicklung, S. 45, hat festgestellt, daß in der StPO von 1952 sowjetisches Recht sehr stark rezipiert worden sei, insbesondere bei der Regelung der Rechtsmittel.

124 So v. Bargen, Strafprozeßordnung in der SBZ, S. 28. 
tersuchungsorgans „durch schriftliche, begründete Verfügung die Einleitung des Ermittlungsverfahrens" anordnen, so daß, wie bei den Verfahren nach Befehl Nr. 201, in politischen Sachen das MfS - das in der StPO als Untersuchungsorgan nicht genannt war - hier in eigener Regie tätig werden konnte. In $\$ 207$ der StPO, der grundsätzlich die "Unmittelbarkeit der Beweisaufnahme“ festlegte, wurden zahlreiche Ausnahmen von diesem Grundsatz aufgenommen, so daß anstelle von richterlichen Protokollen auch das Protokoll einer früheren Vernehmung „durch ein Untersuchungsorgan“ treten konnte, unter anderem dann, „wenn das Erscheinen des Zeugen in der Hauptverhandlung wegen des damit verbundenen Zeitverlustes unzweckmäßig ist". Damit und mit $\ 209$ über die Zulässigkeit der Verlesung früherer Aussagen wurde die Privilegierung der richterlichen Protokolle aufgehoben und die unter ganz anderen Umständen zustande gekommenen Aussagen vor Polizei und MfS diesen gleichgesetzt ${ }^{125}$.

Die SKK stimmte dem Entwurf zwar grundsätzlich zu; ihre am 16. September übergebene Stellungnahme enthielt aber auch eine Reihe von Abänderungsvorschlägen ${ }^{126}$. Bis auf die Aufforderungen, als maximale Frist für die Voruntersuchung drei Monate festzusetzen und die Bestimmung über das abschließende Verhör zu streichen, verfolgten all diese Vorschläge die Absicht, den Beschuldigten in seinen Rechten noch stärker einzuengen, als dies ohnehin schon der Fall war. So sollte das Recht der Zeugen, die Aussagen wegen Verwandtschaft mit dem Beschuldigten zu verweigern, gestrichen werden; dem Beschuldigten war nicht mehr der Haftbefehl, sondern nur noch der Papragraph des StGB zu nennen, aufgrund dessen er verhaftet worden war; eine schwere Erkrankung des Beschuldigten, die eine vorläufige Einstellung des Ermittlungsverfahrens durch das Untersuchungsorgan ermöglichte, mußte von einem Amtsarzt bescheinigt werden; in den $\$ \$ 176$ (Eröffnung des Hauptverfahrens) und 132 (Arrestbefehl des Staatsanwalts) sollten die Termini „Verdachtsgründe“ und „schwerwiegender Verdacht" durch den Ausdruck „genügende Beweise“ ersetzt werden; das Recht des Verteidigers, während der Voruntersuchung mit dem Beschuldigten Kontakt zu halten, sollte entfallen, da dies "die Untersuchung der Sache nur erschweren“ könne; höhere Gefängnisstrafen waren nur dann zur Bewährung auszusetzen, wenn die Hälfte der Strafzeit schon verbüßt wari27.

Am selben Tag wurden die SKK-Vorschläge zusammen mit dem StPO-Entwurf im Politbüro behandelt, das das neue Justizgesetz erwartungsgemäß billigte. Interessanterweise stimmte das Politbüro jedoch nur vier der Abänderungsvorschläge zu (Fristsetzung für die Voruntersuchung, abschließendes Verhör, amtsärztliche Bescheinigung bei Einstellung des Untersuchungsverfahrens und Bewährungsstrafen), während es die einfache Übernahme der anderen Vorschriften „nicht für zweckmäßig“ hielt. Es plädierte für die Beibehaltung des Zeugnisverweigerungsrechts der Angehörigen, wollte dafür aber das Recht der Verwandten, bestimmte Gegenstände nicht herauszugeben, beseitigen. Nach dem Willen des Politbüros sollte dem Beschuldigten nach seiner Verhaftung der Haftbefehl nicht

125 Vgl. dazu Benjamin u.a., Grundriß des Strafverfahrensrechts, S. 47, und Schuller, Geschichte, S. 292.

126 Vermerk Benjamins zur StPO, 16. 9. 1952, BAB, DP1 VA Nr. 8152.

127 Aktenvermerk, o.D., ebenda. 
vorenthalten werden, der den „Grund der Verhaftung“ enthalten mußte; es stellte aber in Aussicht, „durch Anweisung der Gerichte darauf [hinzuweisen], daß als ,ausreichender Grund der Verhaftung ' die Angabe des Gesetzesparagraphen genügt"; statt "genügende Beweise“ wollte es auf die Formulierung „hinreichender Verdacht" ausweichen. Das Recht des Verteidigers auf schriftlichen oder mündlichen Verkehr mit dem Beschuldigten sollte nicht grundsätzlich beseitigt, sondern dadurch eingeschränkt werden, daß der Staatsanwalt die Bedingungen dieses Kontakts festsetzte unter der Maßgabe, daß „der Zweck der Untersuchung [...] nicht gefährdet werden" dürfe. Das Politbüro trug den Änderungswünschen der SKK durchaus Rechnung, war aber darauf bedacht, trotz Übereinstimmung in der Sache eine weniger anfechtbare Form zu wählen. Denn es vertrat die Auffassung, daß die Wirkung der genannten Paragraphen "nicht nur nach Westdeutschland, sondern auch in Kreisen unserer Bevölkerung nicht günstig sein würde"128.

Das höchste SED-Führungsgremium beauftragte Benjamin und die Abteilung Staatliche Verwaltung, wegen der Änderungen der in Karlshorst beanstandeten Paragraphen "nochmals Rücksprache zu nehmen"129. Hinzu kamen Einwände des MfS, deretwegen Benjamin mit Mielke nochmals am 19. September konferierte. Dieser wollte vor allem die ,Arbeitsbedingungen' seiner Behörde weiter erleichtern. Einmal hielt er es „für schwierig“, die richterliche Bestätigung für Beschlagnahmen, Durchsuchungen und Arrestbefehlen innerhalb von 48 Stunden einzuholen, worauf Benjamin sich einverstanden erklärte, statt dessen „unverzüglich“ zu setzen. Zudem hielt er das Ortsprinzip bei der richterlichen Vernehmung nach einer Festnahme "für zu eng“. Mit Benjamin wurde daraufhin vereinbart, daß die richterliche Vernehmung des Beschuldigten an dem Kreisgericht stattzufinden hatte, „in dessen Bereich er festgenommen oder in dessen Bereich die Untersuchung geführt wird“. Auf diese Weise wurde dem MfS ermöglicht, nur ihm genehme Richter heranzuziehen. Auch Mielke mußte die Änderungsvorschläge erst "mit seinem Vertreter in der SKK besprechen“, bevor sie in die StPO aufgenommen werden konnten ${ }^{130}$. Die SKK stimmte den neuen Formulierungsvorschlägen des Politbüros vollständig, den Einwänden Mielkes aber nur teilweise $\mathrm{zu}$, da nur die Durchbrechung des Ortsprinzips, nicht aber die Aufhebung der 48Stunden-Frist festgeschrieben wurde. Nachdem auch die SKK ihr abschließendes Plazet gegeben hatte, konnte der Ministerrat am 25. September die neue Strafprozeßordnung nach Vortrag von Fechner absegnen ${ }^{131}$, bevor sie, gemeinsam mit dem GVG am 2. Oktober von der Volkskammer verabschiedet wurde ${ }^{132}$.

128 Vermerk, o.D., beginnend mit den Worten: „Zu den einzelnen Vorschlägen hat das Politbüro wie folgt Stellung genommen“, ebenda; Protokoll der Politbürositzung, 16. 9. 1952, SAPMO, DY $30 \mathrm{~J}$ IV $2 / 2 / 232$, TOP 8.

129 Ebenda. Im Protokoll wurde die SKK jedoch mit keinem Wort erwähnt.

130 Vermerk Benjamins über die Unterredung mit Mielke am 19. 9. 1952, BAB, DP1 VA Nr. 8152.

131 Protokoll der Regierungssitzung, 25. 9. 1952, BAB, DC 20 I/3, Nr. 136, TOP 4.

132 GBl. 1952, S. 996-1027. 


\section{Die gescheiterte Reform des Strafgesetzbuchs}

Wenngleich das ebenfalls geplante neue Strafgesetzbuch noch auf sich warten ließ, wurde am selben Tag bereits deutlich, was dabei zu erwarten war. Denn die Volkskammer akklamierte ebenfalls dem „Gesetz zum Schutze des Volkseigentums und anderen gesellschaftlichen Eigentums“, das zuvor sowohl vom Politbüro als auch vom Ministerrat - immer gleichzeitig mit dem Entwurf der StPO - gebilligt worden war ${ }^{133}$. Das Gesetz, über das nach einigen geringen Korrekturen ebenfalls Einvernehmen mit Karlshorst herrschte ${ }^{134}$, sah für „Diebstahl, Unterschlagung oder ein sonstiges Beiseiteschaffen von staatlichem oder genossenschaftlichem Eigentum oder von Eigentum gesellschaftlicher Organisationen“ ein- bis dreijährige Zuchthausstrafen vor; in schweren Fällen war sogar auf mindestens zehn Jahre und maximal 25 Jahre Zuchthaus zu erkennen. Zu Recht vermutete der Untersuchungsausschuß Freiheitlicher Juristen in West-Berlin, daß sich darin bereits der "Grundgedanke des kommenden Strafgesetzbuches" widerspiegele135. Die Anwendung des Gesetzes in den folgenden sechs Monaten führte insbesondere durch die harte Aburteilung von Bagatelldiebstählen zu einem bis dahin nicht gekannten Justizterror: Bis März 1953 wurden in 7083 Verfahren insgesamt 10129 Personen zu Zuchthausstrafen verurteilt ${ }^{136}$.

Auch das Strafgesetzbuch wurde im Licht der einschlägigen Gesetze aus der Sowjetunion und den anderen Staaten im sowjetischen Machtbereich überprüft; vor der Abreise der SED-Juristendelegation nach Moskau übersandte Benjamin die Arbeitsergebnisse der vom Politbüro eingesetzten Kommission an Titow in Form eines Vorschlags zur Systematisierung des StGB und von Thesen zu den einzelnen geplanten Abschnitten ${ }^{137}$. Die Ausarbeitung des Strafgesetzbuches in der Regierungskommission nahm sehr viel mehr Zeit in Anspruch als die der anderen Justizgesetze; der festgesetzte Endpunkt der Arbeiten (Ende September) wurde um knapp sechs Wochen überschritten, wozu die Erkrankung von drei der beteiligten Genossen beigetragen hatte. Am 10. November fand nach dreizehn Kommissions- und ebensovielen Unterkommissionssitzungen die Abschlußberatung statt. Da sich die SKK nicht dazu äußerte, konnten auch die DDR-Instanzen nach Abschluß dieser ersten Beratungsphase zunächst nicht weiterarbeiten; auf Drängen Benjamins begannen die Besprechungen mit Karlshorst erst am 29. Dezember 1952. In der damit eingeleiteten zweiten Phase wurden unter Berücksichtigung der sowjetischen Kritik und in Kooperation mit der Abteilung Staatliche Verwaltung der zweite und dritte Entwurf des StGB erarbeitet; letzterer datierte vom 18. März 1953 und wurde am folgenden Tag dem $Z K$ vorgelegt ${ }^{138}$. Die Arbeiten wurden vor allem dadurch verzögert, daß die Entwürfe oftmals längere Zeit

133 Protokoll der Politbürositzung, 16. 9. 1952, SAPMO, DY 30 J IV 2/2/232, TOP 7; Protokoll der Regierungssitzung, 25. 9. 1952, BAB, DC 20 I/3, Nr. 136, TOP 5; GBl. 1952, S. 982.

134 Benjamin an Korobow mit beigefügtem Gesetzesentwurf, 12.9. 1952, BAB, DP1 SE Nr. 1050,

Bl. 432-434; Vermerk Benjamins über Telefonat mit Korobow, 16.9. 1952, BAB, DP1 SE Nr. 3557.

135 Informationsbrief des UfJ, Nr. 33, 15. 11. 1952, S. 256.

136 Vgl. Werkentin, Politische Strafjustiz, S. 69. Volksstaatsanwälte und Volksrichter scheuten vor seiner rigiden Anwendung zurück: vgl. Weber, Justiz und Diktatur, S. $356 \mathrm{f}$.

137 Benjamin an Titow, 21. 5., 29. 5. 1952, BAB, DP1 SE Nr. 1050, Bl. 651, 599.

138 Vorläufiger Schlußbericht über die bisherige Tätigkeit der Regierungskommission, BAB, DP1 SE 
unbearbeitet in Karlshorst liegen blieben; die SKK, die Anfang 1953 mit Führungsproblemen zu kämpfen hatte, mußte immer wieder von Benjamin zur Stellungnahme gedrängt werden ${ }^{139}$. In der dritten Phase schließlich setzte die SED-Führung eine Kommission unter Vorsitz von Rudolf Herrnstadt ein, die den Entwurf nochmals durcharbeitete, einige Änderungen vorschlug und alles den Mitgliedern des Politbüros zuleitete. Größere Auseinandersetzungen wurden offensichtlich nicht mehr erwartet, da dem StGB-Entwurf auch ein Zeitplan bis zur endgültigen Verabschiedung und zur anschließenden Popularisierung des neuen Justizgesetzes beigefügt wurde ${ }^{140}$. In der Politbürositzung vom 14. April wurde dem Entwurf jedoch nur „im Prinzip“ zugestimmt und die endgültige Beschlußfassung auf die nächste Sitzung verschoben ${ }^{141}$. Obwohl die Abteilung Staatliche Verwaltung schnell arbeitete und bereits am 18. April eine neue Fassung vorlegte, kam diese - aus bisher unbekannten Gründen - doch nicht auf die Tagesordnung der folgenden Politbürositzung ${ }^{142}$.

Trotz des schleppenden Gangs der Beratungen bestand nach der grundsätzlichen Zustimmung der SKK vom Februar für Benjamin und die SED-Spitze kein Anlaß zu der Vermutung, daß ausgerechnet die „Freunde“ in Karlshorst dessen Inkrafttreten verhindern würden. Im Mai übergaben diese jedoch Grotewohl ein „Merkblatt“, das eine grundlegende Kritik an dem Gesetzesvorhaben enthielt. Die Beanstandungen gingen im wesentlichen in zwei Richtungen: Zum einen wurde die Unbestimmtheit der Straftatbestände - etwa „Sabotage“ und „Schädlingstätigkeit" - kritisiert, da auf diese Weise zahlreiche Personen für unbedeutende Pflichtverletzungen der Gefahr von Repressalien ausgesetzt würden. Zum anderen wurde das Strafmaß fast durchgehend für zu hoch erachtet. Es fing damit an, daß Handlungen wie das „Nichteinreichen oder nicht termingemäße Einreichen" von Daten bei der Wirtschafts- oder Finanzverwaltung als strafbar bezeichnet wurden, obwohl diese „bei dem augenblicklichen Stand der Entwicklung der DDR nicht strafrechtlich verfolgt werden können“. Andere im Entwurf als Verbrechen bezeichnete Handlungen seien höchstens als „Verletzungen“ zu qualifizieren, da sie „für die Gesellschaft nur eine unbedeutende Gefahr darstellen“. Schließlich stieß die Tendenz des Entwurfs, für zu viele Straftaten ausschließlich die Todesstrafe anzudrohen, auf Kritik: Diese sollte nur "für die allerschwersten Fälle besonders gefährlicher Verbrechen gegen die DDR [...] sowie für schwere Fälle des vorsätzlichen Mordes" vorgesehen werden. Insgesamt forderte die SKK, nicht so sehr auf harte Sanktionen, sondern dort, wo es möglich sei, auf „Warnungen und Maßnahmen erzieherischen Charakters" zu setzen ${ }^{143}$.

139 Vorläufiger Schlußbericht über die bisherige Tätigkeit der Regierungskommission, BAB, DP1 SE Nr. 3360, Bl. 90. Zu den Problemen in der SKK-Führung siehe Scherstjanoi, Einleitung, in: SKKStatut, S. $92 \mathrm{f}$.

140 Betr.: Entwurf eines Allgemeinen Strafgesetzbuches, SAPMO, NY 4090/444, Bl. 150; Plan zur Durchführung des Beschlusses des Politbüros, ebenda, Bl. 11-16.

141 Protokoll der Politbürositzung, 14. 4. 1943, SAPMO, DY 30 J IV 2/2/275, TOP 4.

142 Vorlage der Abt. Staatliche Verwaltung für das Politbüro, 18. 4. 1953, SAPMO, NY 4090/444, Bl. 17. Darauf befindet sich der handschriftliche Vermerk Grotewohls: „Zurück neuer Termin folgt $21 / 4^{4}$.

${ }^{143}$ Merkblatt, o.D., SAPMO, NY 4090/444, Bl. 3-5, mit dem Vermerk Tzschorns: „von sowjetischen Experten überreicht an Gen. O. Grotewohl“; das russische Original Bl. 6-8. Ganz knapp dazu Werkentin, Politische Strafjustiz, S. 42. Daß die SKK die Verabschiedung des StGB verhindert 
Worauf war diese vernichtende Kritik zurückzuführen? Volkmar Schöneburg irrt, wenn er feststellt, daß die sowjetischen Monita an dem StGB-Entwurf "gegen eine unmittelbare Abhängigkeit [der SED-Führung] von Moskau" sprächen, und damit impliziert, die rigiden Strafnormen seien ausschließlich auf justizpolitische Überlegungen der SED-Experten zurückzuführen ${ }^{144}$. Die SKK hatte mit der $\mathrm{Zu}$ stimmung zum Volkseigentumsschutzgesetz und zum StGB-Entwurf im Februar ihre „Freunde“ in der DDR vielmehr in ihren Vorhaben bestätigt, so daß von divergierenden Auffassungen keine Rede sein kann. Als entscheidend muß vielmehr eine Wendung der sowjetischen Innen- und Außenpolitik angesehen werden. Denn drei Wochen nach Stalins Tod wurde mit der Verfügung einer Amnestie am 27. März 1953 eine Abkehr von der rigorosen Strafverfolgung der vergangenen Jahre eingeleitet. ${ }^{145}$ Anfang Mai 1953 brachte der sowjetische Innenminister, Lawrenti Berija, im Präsidium des Ministerrats einen Geheimdienstbericht in Umlauf, in dem nach einem Verweis auf den im ersten Quartal des Jahres 1953 rapide angestiegenen Flüchtlingsstrom erstmals die krisenhafte Situation in der DDR thematisiert wurde. Für die Fluchtbewegung machte der Bericht nicht nur westliche Propaganda, sondern indirekt auch die Forcierung des "Aufbaus des Sozialismus“ seit der 2. Parteikonferenz verantwortlich. Abschließend wurde die SKK darin aufgefordert, ihrerseits Vorschläge für Maßnahmen zur Stärkung der Staatsorgane der DDR auszuarbeiten, die dann vom Präsidium des Ministerrats in Moskau diskutiert werden sollten ${ }^{146}$. Am 18. Mai 1953 berichtet die SKK „weisungsgemäß“ über die Hintergründe der Krise nach Moskau. Unter anderem wies sie auf die große Anzahl ungerechtfertigter Verhaftungen und Verurteilungen sowie auf die unangemessen harte Verfolgung von Wirtschaftsstraftaten hin. Zur Korrektur dieser Fehler sollte eine politische Teilamnestie ausgesprochen, umgehend die Rechtssicherheit wiederhergestellt und weniger bedeutsame Vergehen gesellschaftlichen Gerichten übergeben werden ${ }^{147}$. In dieser Situation überdachte die SKK-Justizabteilung daher die Anwendung des Volkseigentumsschutzgesetzes, dessen harte Strafen nicht mehr undifferenziert alle, sondern vor allem „die böswilligen und besonders schädlichen Diebe am staatlichen und gesellschaftlichen Eigentum" treffen sollten ${ }^{148}$. Es war nur folgerichtig, wenn die SKK auch den StGB-Entwurf nicht in der vorliegenden Form genehmigen wollte und genauer definierte Straftatbestände sowie weniger harte Strafen forderte. Der Zusammenhang des „Merkblatts“ aus Karlshorst mit der geänderten sowjetischen Politik in

hatte, wurde durch Reinartz bald im Westen bekannt (Bericht vom 19.11. 1953, AdsD, Ostbüro 0048a) und auch in westdeutschen Veröffentlichungen erwähnt: siehe Zorn, Entwicklung des sowjetischen Strafrechts, S. 111.

144 Schöneburg, Strafrecht zwischen Machterhalt und Emanzipation, S. 123 (Hervorhebung im Original).

145 Vgl. Hildermeier, Geschichte der Sowjetunion, S. 759.

$146 \mathrm{Zu}$ dem Bericht vom 6. 5. 1953 Bailey/Kondraschow/Murphy, Unsichtbare Front, S. 204 f.; zum Gesamtzusammenhang Scherstjanoi, Sowjetische Deutschlandpolitik, S. 515, die vermutet, daß der Bericht schon auf der Sitzung des sowjetischen Ministerats am 5. 5. 1953 vorlag.

147 Der Inhalt dieses Memorandums von Tschujkow, Judin und Iljitschow an Malenkow referiert bei Scherstjanoi, Semenov und der 17. Juni 1953, S. 917 f.

148 So die Bemerkungen des DDR-Generalstaatsanwalts vom 12.5.1953 unter Bezugnahme auf einen Entwurf Titows, zit. nach Werkentin, Politische Strafjustiz, S. 71; vgl. auch die Rundverfügung vom 26. 5. 1953, BAB, DP1 VA Nr. 6798. 
der DDR, die ja vor allem die Fluchtbewegung unterbinden bzw. rückgängig machen wollte, wird auch daran sichtbar, daß die SKK darin explizit forderte, Rückkehrer aus Westdeutschland nicht generell, sondern nur dann zu bestrafen, wenn diese dort "den Staatsinteressen der DDR Schaden zugefügt haben oder aber in die DDR mit feindlichen Absichten zurückgekehrt sind"149. Die Wendung der sowjetischen Politik, die langfristig den Neuen Kurs einleiten sollte und von der SED nur nachvollzogen werden konnte, war mithin für die harsche sowjetische Kritik an dem StGB-Entwurf verantwortlich und verhinderte eine ähnlich weitreichende Neukodifizierung wie im Fall des Gerichtsverfassungsgesetzes und der Strafprozeßordnung.

Das starke sowjetische Interesse an den Kodifizierungsvorhaben ist vor allem darauf zurückzuführen, daß damit weitgehende deutschlandpolitische Implikationen verbunden waren. Denn eine Modifikation oder gar eine völlige Neufassung der zur Diskussion stehenden zentralen Justizgesetze bedeutete ein weiteres Abrücken von der deutschen Rechtseinheit. Da die Sowjetunion aber auf ihrer Prärogative in der Deutschlandpolitik beharrte, führte sie die DDR im Hinblick auf die Gestalt der neuen Justizgesetze am kurzen Zügel. Im März/April 1952, nach dem Scheitern der Stalin-Noten, kristallisierte sich heraus, daß eine Modifizierung bzw. Neufassung kurz bevorstand. Für die Gerichtsorganisation wurde dies zwingend, als im April 1952 die Entscheidung fiel, die letzten Relikte des Föderalismus auf dem Boden der DDR zu beseitigen. Daher besaß die Neuorganisation des Gerichtsaufbaus und der Justizverwaltung sowohl für die SED-Politiker als auch für die Sowjetunion Priorität. Die Moskaureise der SED-Justizdelegation sollte dann auch vorrangig Anschauungsmaterial in diesen beiden Bereichen liefern. Etwas nachgeordnet waren demgegenüber die Strafprozeßordnung und das Strafgesetzbuch; Handlungsbedarf herrschte vor allem im Hinblick auf das Verfahrensrecht, hatte man doch mit der Erweiterung der Kompetenzen der Staatsanwaltschaft und deren Ausrichtung am sowjetischen Vorbild hier schon einige Vorentscheidungen getroffen. Bei der Ausgestaltung der Strafprozeßordnung standen die staatlichen Verfolgungs- und Repressionsinteressen gegenüber den Rechten des Beschuldigten deutlich im Vordergrund: Auch diese Vorgänge sind somit in den Ausbau der Diktatur im Zeichen des "Aufbaus des Sozialismus" nach der 2. Parteikonferenz einzuordnen. Wollte die SKK diese Ausrichtung der StPO im September 1952 noch forcieren, hatte sich im Mai 1953 der Wind gedreht: Angesichts der krisenhaften Situation in der DDR kam die Zustimmung zu einem Strafgesetzbuch mit einer ebenfalls deutlich repressiven Orientierung nicht in Frage, da die sowjetische Führung bestrebt war, alles zu verhindern, was ein weiteres Anschwellen des Flüchtlingsstroms zur Folge gehabt hätte. 


\section{Justizsteuerung durch das MdJ: Vom Justizbeschluß zum Neuen Kurs}

Aufgrund der massiven Kritik der ZKK an der schwächlichen Anleitung der Justiz durch das MdJ im Sommer 1951 und des Auftrags des Ministerrats vom 23. August, Maßnahmen zur Optimierung der eigenen Arbeit zu entwerfen, brachte die zuständige Hauptabteilung des Ministeriums eine Reihe von Vorschlägen zu Papier, die die Justizsteuerung nachhaltig verbessern sollten ${ }^{150}$. Diese blieben mit den Forderungen nach einem Arbeitsplan für jedes Gericht, regelmäßigen Dienstbesprechungen und Verstärkung der operativen und anleitenden Tätigkeit des MdJ und der Hauptabteilungen Justiz jedoch sehr allgemein und erschöpften sich weitgehend darin, alten Wein in neue Schläuche zu gießen. Der Gedanke, anstelle der bisherigen Revisionspraxis zu einer Instruktionspraxis „mit der Aufgabe konkreter Anleitung" überzugehen, schien zwar neue Perspektiven zu eröffnen, blieb aber unausgeführt und hatte keine unmittelbaren Folgen für die Justizsteuerung. Der einzige wirklich neue Ansatz bestand darin, nicht mehr die „Arbeit des Gerichts im allgemeinen“, sondern die "Leistung jedes einzelnen Richters" zu kontrollieren. Dieser, individualistische“ Ansatz drückte sich auch darin aus, daß jeder Richter ein Diensttagebuch führen und ein Handbuch mit den das Strafprozeßrecht betreffenden Rundverfügungen erhalten sollte.

Mit seinen üblichen Praktiken ging das MdJ daran, die Vorschläge in die Tat umzusetzen, erließ einschlägige Rundverfügungen ${ }^{151}$ und ließ den Hauptabteilungen Justiz in den Ländern einen neuen Plan zur Durchführung von Revisionen zukommen. Im ersten Quartal 1952 führte die Hauptabteilung II selbst Revisionen durch, ihre Mitarbeiter nahmen an Gerichtsverhandlungen teil, Arbeitsbesprechungen mit den Ländervertretern fanden statt; die Referenten der Hauptabteilung analysierten in den wöchentlichen Besprechungen jeweils den Revisionsbericht eines Landes; auf der Grundlage der übersandten Urteile schließlich wurden 14 Richter „auf Schwächen und Fehler in ihren Urteilen hingewiesen“152. Obwohl der Bericht Fechners vor dem Ministerrat über diese und andere Maßnahmen des MdJ am 27. März 1952 „zustimmend zur Kenntnis genommen“ wurde, blieb das Justizministerium, wie der bereits erwähnte Artikel im „Neuen Deutschland" vom 4. April 1952 zeigte, auch weiterhin im Kreuzfeuer der Kritik $^{153}$.

150 Protokoll über die Referentenbesprechung der Hauptabteilung II, 3. 9. 1951, BAB, DP1 VA Nr. 653, Bl. 102; Konzept Böhmes, o.D., BAB, DP1 VA Nr. 575, Bl. 102. Die Vorschläge wurden sowohl in das Gesamtpapier des MdJ als auch in den SED-Justizbeschluß übernommen: siehe Anlage zum Protokoll der Regierungssitzung, 25. 10. 1951, BAB, DC 20 I/3 Nr. 74, TOP 7, und Anlage zum Protokoll der Politbürositzung, 11. 12. 1951, SAPMO, DY 30 J IV 2/2/182, TOP 6.

151 Vgl. u.a. Rundverfügungen Nr. $9 / 52$ (20.12. 1951) über die Durchführung von Arbeits- und Dienstbesprechungen und Nr. 23/52 (24. 1. 1952) über Arbeitspläne der Gerichte und Tagebücher der Richter, in: ANBl. 1952, S. 14-16, $35 \mathrm{f}$.

152 Siehe Bericht über die Durchführung der Beschlüsse des Politbüros zur Verbesserung der Arbeit im Justizapparat vom 20.11. 1951, o.D., BAB, DP1 VA Nr. 263; Berichte über die Arbeit der Hauptabteilung II in den Monaten Januar bis März 1952, BAB, DP1 VA Nr. 6597 (dort auch das Zitat).

153 Protokoll der Regierungsitzung, 27.3. 1952, BAB, DC 20 I/3 Nr. 100, TOP 1, Bl. 3 f.; Zur Arbeit unserer Justizorgane, in: Neues Deutschland, 4. 4. 1952. 
Dies hing höchstwahrscheinlich auch mit den aus Sicht der SED-Spitze verheerenden Ergebnissen einer Überprüfung der Abteilungen I der Staatsanwaltschaften und der politischen Kammern der Land- und Oberlandesgerichte zusammen. Aufgrund des Justizbeschlusses war zu diesem Zweck im Januar 1952 eine zentrale Überprüfungkommission gebildet worden, die sich aus Richard Spank und Gertrud Finke (beide Abteilung Staatliche Verwaltung), Alfred Böhm (Abteilung VI des MfS), Josef Streit (Oberste Staatsanwaltschaft) und einem Vertreter der Hauptverwaltung Deutsche Volkspolizei zusammensetzte. Diese benannte auf einer Sitzung im ZK am 28. Januar Unterkommissionen für jedes Land, die aus zwei Mitarbeitern der SED-Landesleitung und jeweils einem Mitarbeiter aus dem Justizwesen (in der Regel einem Staatsanwalt), aus der Landesverwaltung des MfS und der Landespolizeibehörde bestand. Während die zentrale Kommission die zentralen Justizorgane und die Abteilungen I bei den Landesstaatsanwälten, Oberlandesgerichten und Hauptabteilungen der Justiz in den Ländern überprüfen sollten, waren die Unterkommissionen für die Abteilungen I bei den Oberstaatsanwälten und bei den Landgerichten zuständig. Bis Mitte März hatten letztere ihre Abschlußberichte vorzulegen ${ }^{154}$. Die Feststellungen über die Mängel der inspizierten Gerichte im Abschlußbericht vom 2. April 1952 bezogen sich zum einen auf Äußerlichkeiten wie die Nichteinhaltung von Sicherheitsbestimmungen, mangelhafte Registerführung und die lange Erledigungsdauer der Verfahren. Zum anderen betrafen sie die Rechtsprechung, die für die Nichtanwendung von Strafvorschriften mit überaus harten Sanktionsvorschriften kritisiert wurde: Als Beispiel führte der Bericht eine Verurteilung nach Artikel III A III der Kontrollratsdirektive Nr. 38 an, bei der es sich „offenkundig [um] Boykotthetze gegen demokratische Einrichtungen" gehandelt hätte und daher die Anwendung von Artikel 6 der Verfassung erforderlich gewesen wäre. Außerdem entsprachen „nicht wenige Urteile der Landgerichte [...] weder im Strafmaß noch im Aufbau und der Begründung unserer demokratischen Gesetzlichkeit“. Nur die Oberlandesgerichte erhielten gute Noten, da sie in fast 90 Prozent der Fälle die von den Angeklagten eingelegten Revisionen als unbegründet verworfen hätten. Der Fehler wurde, wie so oft, in der mangelnden Anleitung durch die Hauptabteilungen Justiz der Länder und durch die Hauptabteilung II des MdJ gefunden. So seien etwa die Abteilungen 1 bei den Hauptabteilungen Justiz in Potsdam und Schwerin seit November 1951 nicht besetzt; die Hauptabteilung II des MdJ habe überdies weder diese für politische Strafsachen zuständigen Abteilungen der Landesjustizverwaltung noch die Strafkammern selbst revidiert. Mit einer Reihe von Verbesserungsvorschlägen und der Aufforderung, umgehend elf Richter abzulösen, schloß die Kommission diesen Teil ihres Berichts ${ }^{155}$.

Erst aufgrund dieser massiven Kritik sah sich das MdJ veranlaßt, seine justizsteuernden Aktivitäten zu verstärken. So wurde in der zentralen Besprechung des

154 Arbeitsplan zur Überprüfung der Gerichte und Staatsanwaltschaften, BStU, MfS AS 24/55, Bl. 136-140; Bericht über die Sitzung beim ZK am 28. 1. 1952 zur Überprüfung der Justiz, 29. 1. 1952, ebenda, Bl. $236 f$.

155 Bericht über die Überprüfung der Gerichte und Staatsanwaltschaften Abt. I gemäß Politbürobeschluß vom 11. 12. 1951, ebenda, hier Bl. 208-221. Vgl. dazu auch Engelmann, Staatssicherheitsjustiz, S. 138-140. 
Ministers mit allen Abteilungsleitern am 5. April 1952 beschlossen, daß die Hauptabteilung II einen Kontrollplan aufzustellen hatte und zu den Revisionen alle Abteilungen und Hauptabteilungen des MdJ herangezogen werden sollten; Fechner und Staatssekretär Toeplitz erklärten, an der Revision einiger Gerichte teilnehmen zu wollen ${ }^{156}$. Mit einem solchen Personalaufwand ließ sich die Kontrolle der in politischen Strafsachen tätigen Justizbehörden kurzfristig verstärken: Im zweiten Quartal 1952 wurden die 1. Strafkammern bei den Landgerichten Potsdam, Magdeburg, Meiningen, Leipzig und Zwickau ebenso wie der 1. Strafsenat des Oberlandesgerichts Schwerin und das Dezernat 1 der Landesjustizverwaltung Mecklenburg überprüft und Umbesetzungen an den Landgerichten Gera, Chemnitz und Zwickau vorgenommen ${ }^{157}$. Eine Kontrolltätigkeit in dieser Intensität ließ sich freilich nicht aufrechterhalten: Im zweiten Halbjahr, in dem die zuständige Hauptreferentin in der Hauptabteilung II gut drei Monate ausfiel, erfolgten lediglich zwei Revisionen; Ende 1952 bezeichnete sogar das MdJ den „Stand der Revisionstätigkeit“ als „vollkommen unbefriedigend“158. Das Justizministerium konnte 1952 trotz aller Bemühungen die Kontrolle der Gerichtstätigkeit bei den politischen Strafsachen nicht dauerhaft verbessern. Verantwortlich dafür waren vor allem fehlendes Personal, organisatorische Mängel und der Schlendrian im Fechner-Ministerium, dessen Kräfte freilich auch durch die Reorganisation des Justizwesens im zweiten Halbjahr 1952 gebunden waren.

Die anderen Methoden der Justizsteuerung, die in den Beschlüssen vom Oktober und Dezember 1951 ins Auge gefaßt worden waren, blieben großenteils unwirksam. Dies traf sowohl auf das richterliche Diensttagebuch, das nach der Rundverfügung vom 24. Januar 1952 nicht mehr erwähnt wurde, als auch auf das „Handbuch für das Strafverfahren“ zu. Das Manuskript war zwar im Frühjahr 1952 erstellt worden; seine Herausgabe verzögerte sich jedoch, so daß die Verabschiedung der neuen Strafprozeßordnung seiner Vervielfältigung und Verteilung an die Richter und Staatsanwälte zuvorkam. Trotz gegenteiliger Weisung wurde das Handbuch gedruckt und an die Bezirke ausgeliefert; nachdem der Fehler im Januar 1953 von Reinartz entdeckt worden war, beschloß das Kollegium des MdJ, die bereits ausgegebenen Exemplare wieder einzuziehen und alle „Handbücher“ einzustampfen ${ }^{159}$. Lediglich das Vorhaben, bei der Steuerung der Justiz die Richter individuell zu beurteilen und anzuleiten, wurde ansatzweise verwirklicht. In der Referentenbesprechung der Hauptabteilung II wurde am 19. Mai 1952 erstmals unter der Überschrift „Richterkritik“ festgehalten: „Fehlerhafte Urteile sollen

156 Protokoll der Abteilungsleitersitzung, 5. 4. 1952, BAB, DP1 VA Nr. 6182.

157 Analyse der Rechtsprechung in Strafsachen, die sich gegen die antifaschistisch-demokratische Ordnung richten, Berichtszeitraum 1. 1. 1952-15.6. 1952, BAB, DP1 VA Nr. 293, Bl. 21-41, hier $26 f ., 35,39$.

158 Analyse der Rechtsprechung in Strafsachen, die sich gegen unseren Staat richten, Berichtszeitraum 1. 7.-30. 9. 1952, ebenda, hier Bl. 108; Analyse der Rechtsprechung hinsichtlich der Verbrechen gegen die DDR, Berichtszeitraum 1. 10. 1952-31.12. 1952, ebenda, Bl. 129f. (hier das Zitat). Beide Analysen gingen nach Karlshorst.

159 Vermerk von Reinartz „Zum Handbuch für das Strafverfahren“, BAB, DP1 VA Nr. 1233, Bl. 2630; Beschluß der Kollegiumssitzung, 23. 1. 1953, ebenda, TOP 6, Bl. $36 \mathrm{f}$. Eine etwas andere Darstellung der Vorgänge gaben Benjamin und Fechner bei nachträglichen Befragungen durch das MfS: Aktennotiz der A bteilung IX, 3. 8. 1953, Vernehmungsprotokoll Fechner, 10. 8. 1953, BStU, MfS AU 307/55, Bd. 1, Bl. 75 f., Bl. 93-95. 
von allen Referenten kritisiert werden. Die Kritik ist über die Landesjustizverwaltung an die Landgerichtspräsidenten zu senden. [...] Das gleiche gilt für besonders gute Urteile. Die Abteilung Personal soll eine Mitteilung erhalten, daß wir diese Kritiken nach Richtern geordnet bei uns sammeln." 160 Fortan bildete eine derart formalisierte "Richterkritik“ den Bestandteil zahlreicher Dienstbesprechungen der Hauptabteilung. Wie der SKK berichtet wurde, ermöglichte diese Art der Kontrolltätigkeit, „die bei einzelnen Richtern auftretenden Fehler in der Rechtsprechung schneller als bisher zu analysieren" 161 . Aufgrund ihrer begrenzten Arbeitskapazität konnte die Hauptabteilung freilich nur einen Teil der ihr zugesandten Urteile auswerten; in noch weniger Fällen erfolgte dann eine Weitergabe von Kritik ,nach unten', so daß auch diese Steuerungsmethode die Rechtsprechung nur wenig berührte.

Nicht nur die Richterkritik, die in rudimentärer Form bereits vor 1952 bisweilen angewandt worden war ${ }^{162}$, sondern auch die Absetzung von Richtern wurde 1952 stärker formalisiert. Bis zum Erlaß des neuen GVG galt noch formell Artikel 132, Abs. 5 der DDR-Verfassung, der eine Absetzung von Richtern an die "Genehmigung des Justizausschusses des betreffenden Landtages“ koppelte, obwohl faktisch die Absetzungen in ihrer großen Mehrzahl auf der Grundlage des Tarifrechts vorgenommen wurden ${ }^{163}$. Das Gerichtsverfassungsgesetz vom 2. Oktober 1952 beendete diesen unklaren Rechtszustand: Richter konnten nun entweder nach einer dreijährigen Amtszeit vom Justizminister nicht wieder ernannt $(\mathbb{1 4}$, Abs. 2), oder vorzeitig, "nach Anhörung des Kollegiums des Ministeriums der Justiz" abberufen werden $(\$ 17)$. Die Voraussetzungen einer Abberufung legte $\$ 16$ fest: Dazu zählten neben körperlicher oder geistiger Unfähigkeit und Straffälligkeit auch der Verstoß "gegen die Verfassung oder andere Gesetze" sowie die gröbliche Verletzung ihrer „Pflichten als Richter“. Vor allem letzterer Tatbestand war weit dehnbar und konnte dazu dienen, eine Absetzung aus politischen Gründen zu verschleiern. Die erste Abberufung einer Richterin nach den Vorschriften des neuen GVG erfolgte nach Behandlung des Falles im Kollegium bereits am 5. Dezember 1952164; 16 weitere Richter folgten bis Ende Juni 1953165.

Das Kollegium des Justizministeriums und der Minister der Justiz besaßen bei Abberufungen zwar das letzte Wort; dies bedeutete jedoch nicht, daß die Justizverwaltung immer die Initiative dazu ergriff. Zwei Fälle demonstrieren, daß es oftmals eine Parteiinstanz war, die auf der unteren Ebene die Entfernung von Richtern aus ihren Ämtern betrieb und gegenüber der Justizverwaltung auch durchsetzte. Alois Track, seit Dezember 1951 Vorsitzender Richter der sogenannten „Wirtschaftsstrafkammer“ des Landgerichts Magdeburg, hatte in einer Reihe

160 Protokoll über die Referentenbesprechung, 19. 5. 1952, BAB, DP1 VA Nr. 653/1, Bl. 71; vgl. auch Analyse der Rechtsprechung in Strafsachen, die sich gegen die antifaschistisch-demokratische Ordnung richten, Berichtszeitraum 1. 1. 1952-15. 6. 1952, BAB, DP1 VA Nr. 293, Bl. $39 \mathrm{f}$.

161 Analyse der Rechtsprechung in Strafsachen, die sich gegen unseren Staat richten, Berichtszeitraum 1. 7.-30. 9. 1952, am 6. 11. 1952 an die SKK-Justizabteilung übermittelt, ebenda, hier Bl. 108.

162 Siehe Kap. B.VIII.2.

${ }^{163}$ Siehe Kap. B.III.3.

164 Protokoll der Kollegiumssitzung, 5. 12. 1952, BAB, DP1 VA Nr. 1232, TOP 8, Bl. 85.

165 Siehe die Kollegiumssitzungen vom 24. 12. 1952, BAB, DP1 VA Nr. 1232 und vom 31. 1., 27. 2., 13. 3., 17. 4., 22. 5., 5. 6. und 12. 6. 1953, BAB, DP1 VA Nr. 1233. 
von Fällen die Beschuldigten freigesprochen oder nach Ansicht der SED zu milde Urteile verhängt. Daraufhin galt er der SED-Parteileitung der zuständigen Betriebsparteiorganisation (BPO) als politischer Gegner. Von einer außerordentlichen Parteiversammlung der Magdeburger Justizorgane am 16. Juni 1952 aus der Partei ausgeschlossen und anschließend kurzzeitig verhaftet, wurde er am folgenden Tag fristlos aus dem Justizdienst des Landes Sachsen-Anhalt entlassen ${ }^{166}$. Die Justizverwaltung vollzog nur nach, was die Partei ihr vorgab. Ähnlich gelagert war der Fall des Kreisgerichtsdirektors Willi Pfordte aus Querfurt, der im Herbst 1952 zwei Bauern, die wegen Nichterfüllung ihrer Ablieferungspflichten angeklagt waren, freigesprochen hatte. Als er daraufhin von der Parteileitung der BPO unter Druck geriet, bat er am 20. November 1952 das Justizministerium, ihn von seiner Tätigkeit als Kreisgerichtsdirektor zu entbinden. Kurz darauf, am 24. November, wurde der Fall von der Kreisparteikontrollkommission aufgegriffen, die ein „schwaches Klassenbewußtsein“ und „opportunistisches Verhalten“ bei Pfordte konstatierte; die Leitung der BPO erteilte ihm daraufhin am 12. Januar 1953 wegen seines ,Fehlurteils' und wegen angeblicher anderer Schwächen eine strenge Rüge und verhängte einen zweijährigen Funktionsentzug innerhalb des Partei- und Staatsapparats ${ }^{167}$. Der Leiter der zuständigen Justizverwaltungsstelle in Halle, Gustav Jahn, hatte sich am 4. Dezember indes unter Verweis auf den „übergroßen Richtermangel“ gegenüber dem MdJ gegen ein Ausscheiden des Kreisgerichtsdirektors ausgesprochen und war damit auf Zustimmung gestoßen. Dennoch blieb ihm angesichts des Parteibeschlusses nichts anderes übrig, als Pfordte zu beurlauben und das Justizministerium zu bitten, so schnell wie möglich über dessen Abberufung zu befinden, die nach Zustimmung des Kollegiums mit Schreiben vom 9. Februar auch erfolgte ${ }^{168}$. Dieser Fall wirft ein bezeichnendes Licht nicht nur auf die Macht der Partei, sondern auch auf die Ohnmacht der Justizverwaltung: Ohne sich mit dem Leiter der Justizverwaltungsstelle oder dem $\mathrm{MdJ}$ in Verbindung zu setzen, traf die Parteileitung eine Entscheidung, die beiden zuwiderlief, von diesen gleichwohl umgesetzt werden mußte.

Eine weitere Möglichkeit der Justizsteuerung ergab sich aus dem bis 1953 freilich noch äußerst unterentwickelten Disziplinarrecht ${ }^{169}$. Erst mit den Disziplinarbestimmungen des GVG vom 2. Oktober 1952 (\$\$ 20-24) kündigte sich auch hier eine Wende an: Denn $₫ 24$ forderte ausdrücklich die Ausarbeitung einer Disziplinarordnung für Richter. Bereits vor der Moskaureise geplant, sah sich die SEDJuristendelegation durch die Praxis in der Sowjetunion in ihrem Vorhaben bestätigt ${ }^{170}$; bei der Ausarbeitung der schließlich am 19. März 1953 erlassenen Verordnung171 zog man im MdJ auch die einschlägige sowjetische Rechtsvorschrift

166 Vgl. Witte, Als Richter politisch nicht tragbar, S. 145.

167 Pfordte an MdJ, 20.11. 1952, BAB, DP1 VA Nr. 6534; Sonderbericht über die Sitzung der Kreisparteikontrollkommission am 24.11. 1952, ebenda; Protokoll der Leitungssitzung und anschlieBender Mitgliederversammlung der BPO des Kreisgerichts Querfurt am 12.1. 1953, ebenda.

168 Stellungnahme Jahns, 4. 12. 1952, ebenda; Personalabteilung des MdJ an Kaderabteilung der JVS Halle, 13. 1. 1953, ebenda; JVS Halle an MdJ, 15.1. 1953, ebenda; MdJ an Pfordte, 9.2. 1953, ebenda; Protokoll der Kollegiumssitzung, 31.1. 1953, BAB, DP1 VA Nr. 1233, TOP 9, Bl. 54.

$169 \mathrm{Vgl}$. Lorenz, Disziplinarrecht, S. $379 \mathrm{f}$.

170 Auswertung der Ergebnisse [der Reise in die Sowjetunion], BAB, DP1 VA Nr. 175.

171 GBl. 1953, S. 467-469; zur Entstehung siehe die Vorgänge in: BAB, DP1 VA Nr. 6930. 
heran $^{172}$. Ähnlich wie in der Sowjetunion besaß das MdJ bei Einleitung und Kontrolle der Disziplinarverfahren eine dominierende Rolle173. Der Übergang zwischen Disziplinarstrafen und Abberufung war fließend: Während eines Disziplinarverfahrens konnte festgestellt werden, daß nicht eine Disziplinarstrafe sondern eine Abberufung erforderlich war. Bis zur Entscheidung darüber war nach $₫ 7$ der Verordnung das Verfahren auszusetzen. Wie die Praxis des Jahres 1953 zeigt, betraf dies sieben der vor den Disziplinarausschüssen der Bezirksgerichte und des Obersten Gerichts durchgeführten 16 Verfahren; neun endeten mit einem Verweis, einer Rüge oder einer strengen Rüge ${ }^{174}$. Während mit Disziplinarmaßnahmen überwiegend moralisches Fehlverhalten sanktioniert wurde, setzte das MdJ das Disziplinarrecht bisweilen auch ein, wenn Richter nicht das von ihnen erwartete politische Verhalten zeigten. Dies war beispielsweise bei drei Richtern am Bezirksgericht Halle nach dem 17. Juni 1953 der Fall, die ihre Mitwirkung an der strafrechtlichen Verfolgung der Aufständischen ganz oder teilweise verweigerten: Einer erhielt eine Rüge wegen mangelnden Pflichtgefühls und Verantwortungslosigkeit, der zweite einen Verweis für seine Weigerung, ein „beschleunigtes Verfahren" durchzuführen, und der dritte einen strengen Verweis, da er es abgelehnt hatte, in einem der für politische Sachen zuständigen Senate mitzuarbeiten ${ }^{175}$.

Nach Verkündung der neuen Justizgesetze und der Neuordnung der Justizverwaltung sah sich die SKK-Justizabteilung im Oktober 1952 auch veranlaßt, vom MdJ eine Neuformulierung der Revisionsrichtlinien zu verlangen. Bevor die Direktive an die Justizverwaltungsstellen am 31. Januar 1953 versandt werden konnte, wurde sie von Oberst Jakupow und Hauptabteilungsleiter Böhme am 17. Januar noch einmal durchgesprochen ${ }^{176}$. Die elfseitige Direktive zeichnete sich durch zweierlei aus: eine angestrebte Effizienzsteigerung und eine unverkennbare Schwerpunktsetzung bei der Strafjustiz. Sie verdeutlichte zunächst, daß bei der mindestens einmal jährlich durchzuführenden Revision jedes Kreisgerichts insbesondere die Kader auf ihre „politischen und fachlichen Eigenschaften“, die Rechtsprechung im Hinblick auf die richtige Anwendung der Gesetze und „die Einhaltung der Gesetzlichkeit“ sowie die sonstigen Arbeiten des Gerichts auf ihre sorgfältige Erledigung hin zu überprüfen waren. Vor jeder Revision hatte die Justizverwaltungsstelle die vorhandenen Berichte und Akten des betreffenden Gerichts

172 Bei der Vorlage handelte es sich um den Erlaß des Präsidiums des Obersten Sowjets vom 15.7. 1948 über die disziplinarische Verantwortlichkeit der Richter. Eine Übersetzung der Verordnung wurde Benjamin auf deren Wunsch hin am 22. 10. 1952 übersandt: ebenda. Zu dieser Verordnung vgl. auch Meder, Sowjetrecht, S. 338-340.

173 Nach $\$ 9$, Abs. 2 der Disziplinarordnung erfolgte die Einleitung eines Disziplinarverfahrens aufgrund des Antrags des Justizministers; nach dem sowjetischen Erlaß vom 15.7. 1948 stand dieses Recht dem sowjetischen Justizminister, den Justizministern der Unions- und autonomen Republiken, den Vorsitzenden der Militärtribunale und den Vorsitzenden der den Volksgerichten übergeordneten Gerichten zu. Letztere mußten das zuständige Justizministerium benachrichtigen. Lorenz, Disziplinarrecht, S. $386 \mathrm{f}$., betont mehr die Unterschiede als die Gemeinsamkeiten zwischen den Verfahren in der DDR und der Sowjetunion.

174 Bericht der Kaderabteilung über die Disziplinarverfahren des Jahres 1953, 29. 12. 1953, BAB, DP1 VA Nr. 5599.

175 Vgl. Lorenz, Disziplinarrecht, S. 383, 388.

176 Vermerk Böhmes, 30.10. 1952, BAB, DP1 VA Nr. 706; Vermerk Böhmes über Unterredung mit Jakupow am 17.1. 1953, ebenda. Jakupow monierte freilich nur Kleinigkeiten des Entwurfs vom 15. 12. 1952. 
eingehend $\mathrm{zu}$ studieren, um auf dieser Grundlage anhand eines beigegebenen Schemas einen konkreten Revisionsplan aufzustellen. Als beste Revisionsmethode empfahl das MdJ - wieder unter Rückgriff auf in der Sowjetunion gesammelte Erfahrungen 177 - den Einsatz einer „Brigade“ der Justizverwaltungsstelle, „da sie die Zeit der Revision verkürzt und eine höhere Qualität der Kontrolle gewährleistet“. Bei der Kontrolle der anhängigen Strafverfahren war unter anderem auf die Einhaltung des richtigen Strafmaßes sowie auf den Antrag des Staatsanwalts zu achten. Besondere Aufmerksamkeit lenkte die Direktive ferner auf die „Überprüfung der Verfahren wegen Sabotage und Angriffe auf das Volkseigentum", der eingestellten Verfahren und derjenigen, „in denen ein Freispruch erfolgt" sei. Mit der Revision sollte folglich auch überprüft werden, ob die vorgegebene Schwerpunktsetzung eingehalten wurde und ob die Richter unter Umgehung der harten Strafvorschriften die Täter straffrei ausgehen ließen ${ }^{178}$.

Die Kontrolle der Kreisgerichte wurde fortan vornehmlich von den Justizverwaltungsstellen wahrgenommen, die dem MdJ die Revisionsberichte übersenden und dieses über die Schlußfolgerungen aus den Kontrollen zu unterrichten hatten. Aufgabe des Justizministeriums war die Revision der vierzehn Bezirksgerichte und der Justizverwaltungsstellen. Ob freilich alle im Januar 1953 angesetzten Revisionen bis zum April tatsächlich durchgeführt wurden ${ }^{179}$, ist mehr als zweifelhaft. Dagegen spricht sowohl die Klage einiger Bezirksgerichtsdirektoren, in diesem Zeitraum ohne Anleitung und Kontrolle geblieben zu sein ${ }^{180}$, sowie ein Bericht, demzufolge nur die 1. Strafsenate der Bezirksgerichte Neubrandenburg, Suhl und Potsdam im ersten Quartal des Jahres 1953 überprüft wurden. Selbstkritisch bezeichnete der Bericht für die SKK-Justizabteilung auch die anleitende Tätigkeit des MdJ als gering und ineffektiv: „Die Tätigkeit des Ministeriums der Justiz beschränkte sich im wesentlichen auf eine Kontrolltätigkeit, die noch nicht zu einer allgemeinen Verbesserung der Rechtsprechung führte. "181 Wieder wurde die Krankheit des in der Hauptabteilung II zuständigen Instrukteurs geltend gemacht, aber dies konnte in der Zeit des "verschärften Klassenkampfes“ nach der 2. Parteikonferenz schwerlich ein Argument sein. Die spektakulären Justizkampagnen dieser Monate wurden nicht vom MdJ initiiert: Dies betrifft beispielsweise das seit Herbst 1952 intensivierte justitielle Vorgehen gegen die sogenannten "Großbauern", das auf Veranlassung der Partei im wesentlichen von der Obersten Staatsanwaltschaft propagiert wurde ${ }^{182}$. Das MdJ wandte sich erst am 3. März 1953 mit einer vertraulichen Rundverfügung an alle Gerichte und Justizverwal-

177 Siehe Auswertung der Ergebnisse [der Reise in die Sowjetunion], BAB, DP1 VA Nr. 175.

178 Direktive an die Leiter der JVS, 31. 1. 1953, Betr.: Revisionen der Kreisgerichte durch die Inspekteur-Brigaden der Justizverwaltungsstellen in den Bezirken, BAB, DP1 VA Nr. 706.

179 Protokoll der Kollegiumssitzung, 9. 1. 1953, BAB, DP1 VA Nr. 1233, TOP 4, Bl. 2. Beschlossen wurde die Vorlage Nr. 28 vom 5. 1. 1953, ebenda, Bl. 5-7.

180 So Gustav Jahn (BG Halle) und Jakob Graß (BG Leipzig), in: Stenografische Niederschrift der 12. Arbeitstagung des MdJ, 31. 3. 1953, BStU, MfS AU 307/55, Bd. 5a, Bl. 219, 248; und Friedrich Mühlberger (BG Chemnitz), Warum die Gerichte in den Bezirken nicht auf der Höhe ihrer Aufgaben stehen, in: Neues Deutschland, 19.4.1953.

181 Analyse der Rechtsprechung der 1. Strafsenate der Bezirksgerichte - Verbrechen gegen die Deutsche Demokratische Republik - Berichtszeitraum: 1. 1. 1953-31.3. 1953, am 18. 5. 1953 an SKKJustizabteilung, BAB, DP1 VA Nr. 293, Bl. 144.

182 Vgl. Kap. B.VII.6. 
tungsstellen, in der es sowohl das unzureichende gerichtliche Vorgehen gegen diejenigen kritisierte, die „die Bildung und den Aufbau der Produktionsgenossenschaften zu verhindern, zu verzögern und zu sabotieren" suchten, als auch die mangelnde Härte bei Verfahren wegen Nichterfüllung des Ablieferungssolls. Diesen "Großbauern" waren vielmehr für ihre „klassenfeindliche[n] Aktionen“ harte Strafen aufzuerlegen und deren landwirtschaftliche Betriebe zugunsten der LPGs einzuziehen ${ }^{183}$. Andere derartige Aktivitäten gingen völlig am MdJ vorbei. Dies gilt etwa für die „Aktion Rose“, mit der nach gerichtsförmigen Verfahren zahlreiche Pensions- und Gaststättenbesitzer an der mecklenburgischen Ostseeküste enteignet wurden, um anschließend die Ferienquartiere dem FDGB zur Verfügung stellen zu können. Nach den Verhaftungen im Februar und März 1953 wurden die Angeklagten bis zum 18. April von vier eigens für diesen Zweck gebildeten Strafkammern in Bützow abgeurteilt. Während die Verhaftungen von Vertretern der HVDVP geplant wurden, war für die Organisation der justitiellen Seite der Aktion Josef Streit von der Obersten Staatsanwaltschaft zuständig. Obwohl diese Verfahren, in denen 408 Personen binnen weniger Wochen verurteilt wurden, Richterumsetzungen im Bezirk Rostock sowie die sorgfältige Auswahl der vier Strafkammervorsitzenden erforderten, wurde das $\mathrm{MdJ}$ nicht eingeschaltet. Die Justiz war lediglich auf ihrer mittleren Ebene in Gestalt von Emil Schmiege, dem Direktor des Bezirksgerichts Rostock, an der Steuerung dieser Verfahren beteiligt $^{184}$.

Angesichts der weitgehenden Passivität des Justizministeriums bei der Steuerung einer Strafjustiz, die seit Herbst 1952 mehr und mehr terroristische Züge annahm $^{185}$, ist es auf den ersten Blick erstaunlich, daß das MdJ am 31. März 1953 eine Arbeitstagung einberief, auf der Fechner ausführlich „Über die Schwerpunkte der Rechtsprechung in Strafsachen" referierte. Es handelte sich jedoch nicht um den Versuch, die Initiative auf einem Gebiet zurückzugewinnen, auf dem es diese längst verloren hatte, sondern aller Wahrscheinlichkeit nach um die Ausführung einer Anweisung der ZK-Abteilung Staatliche Verwaltung, die auch die Inhalte des wegweisenden Referats des Justizministers vorgab ${ }^{186}$. Dabei ging es darum, den für die Steuerung der Rechtsprechung auf mittlerer Ebene Verantwortlichen den justizpolitischen Kurs zu verdeutlichen: Eingeladen waren neben Melsheimer und Walter Ziegler die Leiter, die für die Kontrolle der Rechtsprechung zuständigen Oberinspekteure und Kaderleiter der Justizverwaltungsstellen sowie die $\mathrm{Be}$ zirksgerichtsdirektoren. In seinem von Böhme und Oberreferent Gerhard Kelm ausgearbeiteten Referat benannte Fechner die bekannten Schwerpunkte der Rechtsprechung in Strafsachen: Verbrechen gegen die DDR, gegen das Volkseigentumsschutzgesetz, gegen die Landwirtschaftlichen Produktionsgenossen-

${ }^{183}$ RVV 4/53 vom 5. 3. 1953, BAB, DP1 VA Nr. 7568. Gedruckt in: Unrecht als System II, S. 159.

${ }_{184} \mathrm{Vgl}$. zur Aktion Rose Müller, Lenkung der Strafjustiz, hier insbesondere S. $17 \mathrm{f}$., $22 \mathrm{f}$., 147-156, und Werkentin, Politische Strafjustiz, S. 59-63.

185 Diese Bezeichnung legen die rapide ansteigenden Zahlen der Verfahren nach dem Volkseigentumsschutzgesetz (von 218 im Oktober, 506 im November, 966 im Dezember 1952, 1344 im Januar, 1593 im Februar und 2391 im März 1953, ebenda, S. 69) und der Neueingänge bei den 1. Strafkammern der Bezirksgerichte nahe: 622 im 1. Quartal 1952, $821 \mathrm{im} \mathrm{2.,} 997 \mathrm{im} \mathrm{3.,} 1114 \mathrm{im} \mathrm{4.} \mathrm{und} 2196 \mathrm{im}$ 1. Quartal 1953 (Quartalsberichte in: BAB, DP1 VA Nr. 293).

186 So Reinartz in seinem Bericht vom 19.11. 1953 für das SPD-Ostbüro in: AdsD, Ostbüro 0048a. 
schaften, von Privatunternehmern begangene Verbrechen „gegen die fortschreitende Entwicklung und Festigung der sozialistischen Ökonomik “ und Delikte im Haushalts- und Steuerrecht. Absoluten Vorrang räumte er dabei der Rechtsprechung der 1. Strafsenate der Bezirksgerichte ein. Zu jedem Punkt folgten ausführliche Darlegungen, die alle eine Verschärfung der Rechtsprechung bezweckten. Fechner bemängelte beispielsweise die häufige Nichtanwendung von Artikel 6, die Umgehung des Volkseigentumsschutzgesetzes vor allem dann, wenn es um die Entwendung geringer Mengen ging, sowie die bei Verurteilungen nach diesem Gesetz undifferenzierte Anwendung der Mindeststrafe von einem Jahr Zuchthaus ${ }^{187}$.

In der Diskussion bestätigten der Leiter der Justizverwaltungsstelle Gera, Herbert Lemnitzer, und Bezirksgerichtsdirektor Gustav Jahn (Halle), daß die meist aus der Arbeiterklasse stammenden Richter bei Verurteilungen nach dem Volkseigentumsschutzgesetz nicht über die Mindesstrafe hinausgingen oder sogar von einer Bestrafung absahen, da es sich bei der überwiegenden Mehrzahl der Täter ebenfalls um Arbeiter handelte. Melsheimer wollte das Argument der Klassensolidarität nicht gelten lassen und rechtfertigte die hohen Mindeststrafen: Die Leitlinien der Strafrechtsprechung in der DDR waren folglich rein politischer, aber keineswegs klassenpolitischer Natur. Neben Fechner nutzten auch der Generalstaatsanwalt und Ziegler die Gelegenheit zu justizsteuernden Anweisungen. Melsheimer etwa machte in dieser Runde seine Anweisung an die Staatsanwälte bekannt, bei politischen Sachen die Öffentlichkeit grundsätzlich auszuschließen, und rief dazu auf, dem MfS zu vertrauen, wenn dieses Beweismaterial vernichtet habe: Einem „politisch richtig denkenden Richter" müsse es genügen, wenn im Untersuchungsbericht von übler Hetze seitens des Angeklagten die Rede sei. Ziegler wiederum stellte die Praxis mancher Bezirksgerichte, anfallende Rechtsmittel weitgehend durch Beschluß zu verwerfen, als Maßnahme dar, die deren Arbeit erleichtern könne ${ }^{188}$. Auch wenn das Justizministerium erst relativ spät in die Kampagne zur Verschärfung der politischen Strafverfolgung eingeschaltet worden war, wollte es nun , am Ball bleiben': Daher wurde das Referat Fechners in der "Neuen Justiz" abgedruckt, eine die Ergebnisse der Arbeitstagung enthaltende „Richtlinie für die Verbesserung der Arbeit der Gerichte und Organe der Justizverwaltungen" am 5. Mai 1953 verschickt ${ }^{189}$ und am 12. Mai eine weitere Arbeitstagung mit demselben Teilnehmerkreis wie sechs Wochen zuvor im MdJ abgehal$\operatorname{ten}^{190}$.

187 Fechner, Über die Schwerpunkte der Rechtsprechung, S. 225, 227. Es handelte sich nicht, wie auch an dieser Stelle behauptet wird, um die 12., sondern um die zweite derartige Arbeitstagung: siehe dazu die wohl von Gerda Grube stammende, nicht gezeichnete Aufzeichnung, o.D., in: BStU, MfS AU 307/55, Bd. 7, Bl. 288.

188 Stenografische Niederschrift der 12. [sic] Arbeitstagung des MdJ, 31. 3. 1953, BStU, MfS AU $307 /$ 55, Bd. 5a, Bl. 220-224, $207 \mathrm{f}$. (Melsheimer), 188f., 191 (Lemnitzer), 217f. (Jahn), $231 \mathrm{f}$. (Ziegler).

189 Richtlinie für die Verbesserung der Arbeit der Gerichte, o.D., BAB, DP1 VA Nr. 5578. Böhme hatte die Richtlinie im Auftrag Fechners entworfen; diese war mehrfach im Kollegium des MdJ diskutiert worden, bevor am 2.5. 1953 beschlossen wurde, sie am 5.5. zu versenden: Vorlage Nr. 47, BAB, DP1 VA Nr. 1233, Bl. 132-140, Kollegiumssitzungen vom 2.4., 17. 4, 24. 4., 2. 5. 1953, ebenda, Bl. 129, 154, 177, 210.

190 Dies geht aus den Kollegiumssitzungen am 2.5., 11. 5. und 22. 5. 1953 hervor, ebenda, Bl. 210f., $233,235$. 
Kurz bevor diese Aktivitäten einsetzten, wurde die mangelhafte Steuerungstätigkeit des MdJ öffentlich thematisiert. Am 19. April erhielt der Direktor des Bezirksgerichts Chemnitz, Friedrich Mühlberger, im „Neuen Deutschland“ Gelegenheit, ausgehend von der Arbeitstagung vom 31. März das Justizministerium heftig anzugreifen. Die Gerichte hätten vor der Arbeitstagung weder eine regelmäßige Anleitung von ,oben' noch Gelegenheit zum Erfahrungsaustausch erhalten; Hauptabteilungsleiter Böhme habe sogar den Bezirksgerichtsdirektoren am 28. Januar regelrecht untersagt, sich untereinander über die eigenen Arbeitspläne zu unterrichten, und darauf bestanden, daß ein Erfahrungsaustausch nur über das Ministerium erfolgen könne. Auch mit der Arbeitstagung habe sich an diesem $\mathrm{Zu}$ stand nichts geändert, da auch bei dieser Gelegenheit keine Hinweise für die Abfassung eines Arbeitsplanes für das zweite Quartal gegeben worden seien. Außerdem bemerkte Mühlberger: „Die unkritische Art, an Fragen heranzugehen, die fehlende kämpferische Auseinandersetzung, die Unterdrückung der Kräfte der Kritik im Apparat des Ministeriums der Justiz konnten die Teilnehmer der Arbeitstagung nicht davon überzeugen, daß ihnen von jetzt ab das Ministerium mehr Hilfe angedeihen lassen wird. Das Versprechen, monatliche Arbeitsbesprechungen mit den Direktoren durchzuführen, ist ebenfalls schon so oft gegeben, aber nicht gehalten worden. " ${ }^{191} \mathrm{Daß}$ ein dem MdJ unterstellter Bezirksgerichtsdirektor eine derart vernichtende Kritik veröffentlichen durfte, verweist darauf, daß dieser im Auftrag der SED-Spitze handelte. Möglicherweise hatte Benjamin den Artikel angeregt, der das immer wieder im Verlauf der Tagung von Fechner betonte Verbot an die Bezirksgerichte, irgendwelche Unterlagen, insbesondere aber Arbeitspläne an das Oberste Gericht oder auch untereinander zu versenden ${ }^{192}$, übel aufgestoßen sein mußte.

Durch diesen Artikel fühlte sich die Spitze des Ministeriums genötigt, nicht nur ihre Aktivitäten zur Durchsetzung des harten strafpolitischen Kurses weiter zu verfolgen, sondern auch die von Fechner am 31. März in Aussicht gestellte Reorganisation der Hauptabteilung II "an Haupt und Gliedern“ beschleunigt in Angriff zu nehmen ${ }^{193}$. Bereits am 20. März war im Kollegium die Arbeitsweise der Hauptabteilung II kritisch diskutiert worden; im April legten sowohl Abteilungsleiter Reinartz als auch Hauptabteilungsleiter Artzt Reformvorschläge vor ${ }^{194}$. Noch unter dem Eindruck der vernichtenden Kritik im „Neuen Deutschland“ beschloß das Kollegium am 24. April, die Hauptabteilung II durch den Oberreferenten Gehard Häusler zu verstärken, der nach Absolvierung eines Jura-Studiums und eines Teils seines Referendardienstes seit 1951 in der Hauptabteilung I tätig war ${ }^{195}$. Langfristig sollte er die Leitung der Hauptabteilung übernehmen. Das

191 Friedrich Mühlberger, Warum die Gerichte in den Bezirken nicht auf der Höhe ihrer Aufgaben stehen, in: Neues Deutschland, 19. 4. 1953.

192 Stenografische Niederschrift der 12. [sic] Arbeitstagung des MdJ, 31.3. 1953, BStU, MfS AU $307 /$ 55, Bd. 5a, Bl. 204, 215 f., 244, 255, 261.

193 Ebenda, Bl. 259.

194 Protokoll der Kollegiumssitzung, 20. 3. 1953, BAB, DP1 VA Nr. 1233, TOP 3, Bl. 90 f.; Vorlage Nr. 45 von Reinartz, 7. 4. 1953, ebenda, Bl. 149-152; Vorlage Nr. 50 von Artzt, 22. 4. 1953, ebenda, Bl. 212-218. Diese Vorlage lag der Kollegiumssitzung am 24. 4. 1953 vor.

195 Vgl. Lebenslauf Häuslers und MdJ an MdI, Hauptabteilung Personal, 10. 5. 1952, BAB, DP1 SE Nr. 74. 
Kollegium berief ebenfalls Häusler, Grube und Reinartz in eine Kommission, die auf der Grundlage der bisherigen Vorschläge ein umfassendes Exposé zur Reform der Hauptabteilung auszuarbeiten hatte ${ }^{196}$. Die „Vorschläge zur Reorganisation der Hauptabteilung II“, die in der Kollegiumssitzung vom 2. Mai 1953 „als Ganzes gebilligt" wurden und nur noch leicht verändert werden sollten, gingen im wesentlichen in drei Richtungen. Anvisiert war erstens eine Optimierung der Revisionstätigkeit vor allem durch zentral gelenkte, regelmäßige Spezialrevisionen. Zweitens sollten von nun an nicht mehr Einzelanweisungen im Mittelpunkt stehen; die aus den Revisionen gewonnenen Erkenntnisse waren vielmehr zu verallgemeinern und an alle interessierten Stellen in Form von Hinweisen weiterzuleiten. Schließlich war der durch die umfangreiche Berichterstattung entstandene Papierkrieg in der Hauptabteilung durch eine drastische Einschränkung der Berichtspflichten zu begrenzen ${ }^{197}$. Ein erster Schritt in diese Richtung stellte die vertrauliche Rundverfügung vom 19. März dar, derzufolge nur noch Straf- und Zivilurteile von besonderer Bedeutung von den Gerichten zu übersenden waren: Nur so bestand auch die Möglichkeit, die eingehenden Urteile auszuwerten, was zuvor vorwiegend an der Papierflut gescheitert war. Voraussetzung für eine effektive Justizsteuerung war eine enge Zusammenarbeit der drei zentralen Justizorgane und der Volkspolizei, da nur so die „Schwerpunkte“ der Rechtsprechung rechtzeitig festgestellt werden konnten. Der Vorschlag des Exposés, einen monatlichen Erfahrungsaustausch zwischen den vier angesprochenen Behörden zu organisieren, hatte angesichts der Spannungen zwischen Fechner auf der einen und Benjamin und Melsheimer auf der anderen Seite vorerst keine Chance, befolgt zu werden ${ }^{198}$. $\mathrm{Ob}$ die vorgesehenen Modifikationen in der Steuerung, die nach wie vor mit dem alten Instrumentarium operierte, dem Justizministerium den gewünschten Erfolg beschert hätten, bleibt zweifelhaft. Auch wenn in dem Exposé die Revisoren nun „Instrukteure“ genannt wurden, lag der Schwerpunkt der Arbeit der Hauptabteilung II nach wie vor auf der Kontrolltätigkeit.

Zwei Ereignisse im Juni 1953 sollten freilich die Richtung und die Methoden der Justizsteuerung sehr viel nachhaltiger ändern als diese Vorgänge im MdJ: die Proklamation des Neuen Kurses und der Volksaufstand vom 17. Juni. Die Entscheidung, vom forcierten „Aufbau des Sozialismus“ in der DDR abzurücken, fiel in einer Sitzung des Ministerrats der UdSSR am 27. Mai 1953199. Die auf diesem Beschluß basierende Verfügung des Ministerrats200 wurde am 2. Juni Ulbricht, Grotewohl und Oelßner in Moskau vorgelegt; unmittelbar nach ihrer Rückkehr nach Ost-Berlin machten sie sich an die Umsetzung der sowjetischen Weisung und leiteten damit einen Kurswechsel in der DDR ein. Bereits am 5. Juni wurde

196 Protokoll der Kollegiumssitzung, 24. 4. 1953, ebenda, TOP 2, Bl. $177 \mathrm{f}$.

197 Darin bestand in der Erinnerung Scheeles das Hauptmotiv zur Reorganisation der Hauptabteilung II: Bericht Scheeles, BStU, MfS AU 307/55, Bd. 6, Bl. 175.

198 Vorlage Nr. 51, 29. 4. 1953, BAB, DP1 VA Nr. 1233, Bl. 219-228; Protokoll der Kollegiumssitzung, 2. 5. 1953, ebenda, TOP 2, Bl. 210. Zu den Vorschlägen siehe auch Künzel, Ministerium der Justiz, S. $209 \mathrm{f}$.

199 Zum Hintergrund und zur Ministerratssitzung Scherstjanoi, Sowjetische Deutschlandpolitik, S. 513-521.

200 Stöckigt, Dokument von großer historischer Bedeutung; eine Vorlage dazu aus dem sowjetischen Außenministerium in: Scherstjanoi, Sowjetische Deutschlandpolitik, S. 543-546. 
im Politbüro zur Vorbereitung der notwendigen Beschlüsse eine Reihe von Kommissionen gebildet, darunter auch eine für Rechtsfragen ${ }^{201}$. Die sowjetische Führung hatte im Zusammenhang mit Recht und Justiz drei Vorgaben gemacht. Die erste bestand in einer Änderung der Richtung der Strafrechtsprechung: Angemahnt wurden mehr Rechtssicherheit, eine bessere Behandlung der Beschuldigten und der Verzicht auf drakonische Strafmaßnahmen für Bagatellfälle. Zweitens waren die Fehler der Vergangenheit dadurch zu korrigieren, daß Gerichtsurteile überprüft und die Verurteilten gegebenenfalls amnestiert wurden. Drittens schließlich sollten auch die Strafgesetze geändert werden, die den Auswüchsen der Justizpraxis zugrunde gelegen hatten.

Das Politbüro hatte in seinem Kommuniqué vom 9. Juni vor allem die unmittelbar bevorstehenden Aufgaben im Auge, als es dazu aufforderte, diejenigen zu entlassen, die nach Volkseigentumsschutzgesetz zu ein bis drei Jahren Haft verurteilt waren oder verurteilt werden sollten. Der Ministerrat ging in seinem Beschluß drei Tage später insofern weiter, als er Justizministerium und Generalstaatsanwalt beauftragte, „alle Verhaftungen, Strafverfahren und Urteile sofort zu überprüfen"202. Die Anweisung des Politbüros führte innerhalb von zwei Tagen zur Entlassung von 4000 Häftlingen ${ }^{203}$. Ebenso zügig ging das Kollegium des MdJ vor, das am 12. Juni entschied, auf der nächsten Arbeitstagung mit den Leitern der Justizverwaltungsstellen und den Bezirksgerichtdirektoren das Thema: „Die neuen Aufgaben der Justiz unter Berücksichtigung der Beschlüsse des Ministerrats" zu behandeln. Die Besprechung sollte vom 23. auf den 16. Juni vorverlegt und Vertreter des Obersten Gerichts, der Obersten Staatsanwaltschaft, der SKK und des ZK ebenfalls eingeladen werden. In der Zwischenzeit hatte eine Kommission eine Direktive für die Gerichte und Justizverwaltungen auszuarbeiten, die bei der Arbeitstagung zu erläutern und den Justizfunktionären auszuhändigen war ${ }^{204}$. Die MdJ-Anleitung entsprach völlig der Beschlußlage: Auf eine allgemeine Ermahnung zur Stärkung der Rechtssicherheit durch strikte Beachtung der Unabhängigkeit der Richter in ihrer Rechtsprechung und genaue Einhaltung aller Verfahrensvorschriften folgte eine lange Aufzählung der zu überprüfenden Gruppen von Strafverfahren. Die Anleitung führte vornehmlich wirtschaftsstrafrechtliche Prozesse, aber auch solche auf, in denen die Anklage auf Artikel 6 der Verfassung, Artikel III A III, Kontrollratsbefehl Nr. 2 (illegaler Waffenbesitz) und Widerstand gegen die Staatsgewalt gestützt wurde ${ }^{205}$.

Der politische Kurswechsel kam jedoch zu spät und zu abrupt. Als man sich in den Bezirken an die Umsetzung der Direktive machte, streikten und demonstrierten in Ost-Berlin bereits die Bauarbeiter. Die Demonstrationen schwollen an, ris-

$201 \mathrm{Vgl.} \mathrm{zu}$ diesen Vorgängen insgesamt Scherstjanoi, Wollen wir den Sozialismus?, S. 658-661.

202 Kommuniqué des Politbüros, 9. 6. 1953, in: Dokumente der SED, Bd. 4, S. 429-431, hier 430f.; Mitteilung über den Ministerratsbeschluß in: Spittmann/Fricke, 17. Juni 1953, S. 204 f.

${ }^{203} \mathrm{Vgl}$. Werkentin, Politische Strafjustiz, S. 117.

204 Protokoll der Kollegiumssitzung, 12.6. 1953, BAB, DP1 VA Nr. 1233, Bl. 250f. Vgl. auch den Bericht Scheeles, o.D., BStU, MfS AU 307/55, Bd. 6, Bl. 189-192, über die positive Reaktion Fechners auf den Kurswechsel. Die Kommission setzte sich aus Toeplitz, Böhme, Reinartz und Artzt zusammen.

${ }^{205}$ Anleitung für die Gerichte und die Organe der Justizverwaltung, 15.6. 1953, BAB, DP1 VA Nr. 7582. 
sen auch andere Bevölkerungsgruppen mit und erweiterten sich am 17. Juni zu einer Volkserhebung in der ganzen DDR ${ }^{206}$. Der Aufstand, der nur mit Hilfe sowjetischer Truppen unterdrückt werden konnte, hatte ein justitielles Nachspiel, in dessen Verlauf bis zum 5. Oktober 1953 insgesamt 1240 Teilnehmer von DDRGerichten verurteilt wurden. Von diesen Verurteilten erhielten 468 (41,4 Prozent) lediglich eine Freiheitsstrafe von bis zu 12 Monaten $^{207}$. Die relativ hohe Anzahl an leichten Gefängnisstrafen, die auch in dem Bericht des sowjetischen Hohen Kommissars kritisch kommentiert wurde, war auf die Zwangslage der SED-Führung nach dem Aufstand zurückzuführen. Allein aufgrund der weiterhin gültigen sowjetischen Anweisungen konnte sie nicht vom Neuen Kurs abweichen, mußte die Aufständischen aber bestrafen. Die Lösung des ZK der SED bestand darin, „mit größter Sorgsamkeit zu unterscheiden zwischen den ehrlichen, um ihre Interessen besorgten Werktätigen, die zeitweise den Provokateuren Gehör schenkten - und den Provokateuren selber“208. Dies erforderte Urteile, die im Strafmaß stark differenzierten. Die Staatsanwälte und Richter, die bis zur Verkündung des Neuen Kurses zu weitgehender Härte angewiesen, danach aber zurückgepfiffen worden waren, bedurften nach Auffassung der SED-Führung bei dieser heiklen Aufgabe einer intensiveren Anleitung als bisher. Daher wurde am 20. Juni 1953, als das Politbüro den Justizminister und den Generalstaatsanwalt beauftragte, die „erforderlichen Maßnahmen zu treffen, damit die im Zusammenhang mit den Ausschreitungen der letzten Tage Verhafteten ab Sonntag, den 21. Juni 1953 zur Aburteilung gelangen"209, auf Anweisung von Plenikowski ein „Operativstab" gebildet, der die entsprechenden Strafverfahren anzuleiten hatte210. Diesem Anleitungsgremium unter Benjamins Vorsitz gehörten Vertreter aller drei zentralen Justizorgane an: Haupabteilungsleiter Böhme vom MdJ, Helene Kleine vom Obersten Gericht und Staatsanwalt Rudolf Wunsch von der Obersten Staatsanwaltschaft ${ }^{211}$. Der im Gebäude des Obersten Gerichts ansässige Operativstab verfügte darüber hinaus über eine Reihe von Instrukteuren - vom MdJ Gerda Grube und Erna Naumann ${ }^{212}$-, die die Weisungen aus Ost-Berlin an die Bezirksgerichte weitergaben, die Rechtsprechung kontrollierten und in unklaren Fällen telefonisch um Anleitung baten. Der Operativstab wiederum behandelte die eingehenden Informationen in täglichen Besprechungen und hielt ständigen Kontakt mit der ZK-

206 Zur Erhebung des 17. Juni vgl. vor allem die seit 1990 erschienen Veröffentlichungen: Diedrich, 17. Juni 1953; Hagen, DDR - Juni '53; Mitter/Wolle, Untergang auf Raten, S. 27-162; Kowalczuk/ Mitter/Wolle, Tag X.

207 Bericht des sowjetischen Hohen Kommissars über die politische und wirtschaftliche Lage der DDR im 3. Quartal, in: Foitzik, Berichte des Hohen Kommissars, S. 1375. Bis Ende Januar 1954 steigerte sich diese Zahl auf 1526: vgl. Werkentin, Politische Strafjustiz, S. 162. Hinzu kommt eine unbekannte Zahl von Verurteilungen durch die Sowjetischen Militärtribunale.

208 Beschluß des ZK der SED „Über die Lage und die unmittelbaren Aufgaben der Partei“, 21.6. 1953, in: Dokumente der SED, Bd. 4, S. 436-445, hier 441.

${ }^{209}$ Protokoll der Politbürositzung, 20.6. 1953, SAPMO, DY 30 J IV 2/2/291, TOP 5; vgl. Werkentin, Politische Strafjustiz, S. 124.

210 Ebenda; siehe auch Bericht Scheeles, o.D., BStU, MfS AU 307/55, Bd. 6, B1. 232.

211 So Werkentin, Politische Strafjustiz, S. 124. Nach dem Bericht von Reinartz für den UfJ gehörten dem Operativstab zusätzlich noch Melsheimer und Walter Ziegler vom Obersten Gericht an: Unrecht als System II, S. 78. Scheele zufolge gehörte auch der Minister für Staatssicherheit, Wilhelm Zaisser, dem Stab an; dies wird durch den Bericht des sowjetischen Hohen Kommissars gestützt: vgl. Foitzik, Berichte des Hohen Kommissars, S. 1374.

212 Feth, Benjamin, S. 145, nennt irrtümlicherweise Hilde Neumann an Stelle von Erna Naumann. 
Abteilung Staatliche Verwaltung sowie den sowjetischen Dienststellen in Karlshorst ${ }^{213}$. Das MdJ und dessen Hauptabteilung II konnten somit nur im Rahmen dieses engmaschigen Anleitungssystems wirken; über eigenen Handlungsspielraum verfügte es dabei nicht ${ }^{214}$. Auch mit dem Operativstab konnte jedoch nicht eine flächendeckende Steuerung der Verfahren erreicht werden; zusätzliche Verwirrung stiftete bei den Richtern die von Fechner am 30. Juni in einem Interview im „Neuen Deutschland“ ausgegebene Richtlinie: „Es dürfen nur solche Personen bestraft werden, die sich eines schweren Verbrechens schuldig gemacht haben. Andere Personen werden nicht bestraft. Das Streikrecht ist verfassungsmäßig garantiert." Nachdem Ulbricht wieder fest im Sattel saß und Fechner verhaftet worden war, bekamen die Justizfunktionäre, die sich an diese Direktive gehalten hatten, wieder Probleme ${ }^{215}$. Auch nach dem 17. Juni funktionierte die Justizsteuerung nicht immer so reibungslos, wie es manchmal den Anschein hat.

Als der Operativstab Ende August 1953 seine Arbeit einstellte, wurde die Kontrolle der infolge des 17. Juni durchgeführten Strafverfahren wieder der Hauptabteilung II überantwortet: Fritz Böhme waren sowohl die Meldungen der Staatsanwaltschaft als auch die Urteile vorzulegen, bevor sie mit einer kurzen Kritik an den Generalstaatsanwalt weitergeleitet wurden ${ }^{216}$. Das MdJ erhielt unter gewandelten Bedingungen aber nicht nur einen Teil seiner Steuerungskompetenz zurück, sondern behielt auch das System der Anleitung der Gerichte und Justizverwaltungstellen durch Justizinstrukteure bei. Beides war vor allem an zwei Voraussetzungen gekoppelt: die Übernahme des MdJ nach der Verhaftung Fechners durch Hilde Benjamin im Juli 1953 und die damit einhergehende grundlegend verbesserte Kooperation zwischen Oberstem Gericht, Oberster Staatsanwaltschaft und Justizministerium. Denn im Unterschied zu Fechner war Benjamin fähig und willens, die Einführung neuer Steuerungsmethoden im MdJ zu forcieren und die Position des Justizministeriums innerhalb des Justizsteuerungssystems zu verteidigen und auszubauen. Aufgrund ihrer Betätigung am Obersten Gericht und ihrer engen Freundschaft mit Generalstaatsanwalt Melsheimer war sie wie keine andere dazu prädestiniert, die Bande zwischen den drei obersten Justizorganen enger zu knüpfen. Schon wenige Tage nach ihrem Amtsantritt im Justizministerium am 18. Juli setzte sie dieses Problem auf die Tagesordnung der Kollegiumssitzung. Unter Zustimmung von Melsheimer und Schumann, die ebenfalls anwesend waren, beschloß das Kollegium am 24. Juli zahlreiche Koordinierungsmaßnahmen bei der Justizsteuerung: Diese umfaßten wechselseitige Abstimmungen der jeweiligen Arbeitspläne, gemeinsame Auswertung von überprüften Urteilen durch $\mathrm{MdJ}$ und Oberstes Gericht, Austausch von Revisionsberichten und Rechtsprechungsanalysen sowie von Arbeitsberichten der Staatsanwaltschaft zwischen MdJ und Oberster Staatsanwaltschaft, Teilnahme eines Richters des Obersten Gerichts an

${ }^{213}$ Vgl. dazu insgesamt Werkentin, Politische Strafjustiz, S. 124-129.

214 Reinartz behauptete sogar, daß der Operativstab mit dem Ziel gebildet worden sei, „Fechner und die Hauptabteilung Rechtsprechung des Justizministeriums irgendwie auszuschalten": siehe Unrecht als System II, S. 78.

215 Vgl. dazu aus regionaler Perspektive Weber, Justiz und Diktatur, S. 383-385; Pohl, Justiz in Brandenburg (Manuskript), S. 234.

216 Vgl. Werkentin, Politische Strafjustiz, S. 132. Die Formulierung, daß alle Urteile „zunächst“ Böhme vorzulegen waren, scheint zu implizieren, daß dies vor deren Verkündung geschah. 
den Gerichtsrevisionen des MdJ, gemeinsame Abstimmung grundsätzlicher Rundverfügungen, laufende Information des MdJ über die Gerichtskritiken des Obersten Gerichts, regelmäßige Übersendung aller Urteile des Obersten Gerichts an das MdJ, eine Verständigung über die Einberufung zu Arbeitstagungen von Richtern, die grundsätzlich vom $\mathrm{MdJ}$ vorgenommen werden sollten, sowie wechselseitige Teilnahme an den Leitungsbesprechungen der jeweiligen Behörden ${ }^{217}$. Dies bedeutete zwar nicht, daß fortan das Verhältnis zwischen den drei obersten Justizbehörden völlig ungetrübt sein sollte: Weder das systembedingte Konkurrenzverhältnis noch persönliche Spannungen ${ }^{218}$ konnten auf diese Weise ausgeräumt werden. Durch die Fixierung von Koordinations- und Abstimmungsverfahren, die eine gewisse Regelmäßigkeit der Kontakte einschlossen, war jedoch eine wesentliche Voraussetzung für eine einheitliche Justizsteuerung von der Zentrale aus gegeben.

Die Übernahme des Instrukteursystems durch MdJ und Oberste Staatsanwaltschaft sollte deren Effektivität in der Anleitung der Rechtsprechung erhöhen. Bei den für die Bezirksgerichte und Justizverwaltungsstellen gedachten Instruktionen kam es vor allem darauf an, neue Weisungen „vom Ministerium für die Anleitung der Gerichte den Richtern schnell zu übermitteln und zu erläutern sowie Signale aus den Bezirken schnell zur Kenntnis des Ministeriums zu bringen und auszuwerten"219. Während das MdJ Ende November 1953 noch mit Einzelinstrukteuren arbeitete, setzte es bis zum April 1954 - wie der Generalstaatsanwalt - auch "Instrukteurbrigaden" ein ${ }^{220}$. Instruktionen hatten in regelmäßigen Abständen zu erfolgen, die zwischen vier bis acht Wochen liegen sollten; jeder Instrukteur sollte mindestens ein Jahr seinen Wirkungskreis behalten; die Instruktionen hatten nach einem festgelegten Plan zu erfolgen, der zuvor in einer Besprechung im MdJ abgesegnet werden mußte. Dies bedeutete, daß es nun nicht mehr primär um konkrete Anweisungen für die Rechtsprechung in einzelnen Verfahren ging; die Inhalte einer Instruktion sollten vielmehr in flexibler Weise zentrale Anweisungen aufgrund von neuen Gesetzen, Verordnungen und sonstigen Bestimmungen mit Kenntnissen über die lokalen Verhältnisse in Rechtsprechung und Justizwesen miteinander verbinden. Vor diesem Hintergrund beschrieb Benjamin die Tätigkeit des Instrukteurs einmal als „die unmittelbare Transmission der politischen Leitung von oben nach unten“. Und sie fuhr fort: „Der Instrukteur ist der Träger für alles Neue, das an die Richter heranzubringen ist. Er ist Helfer und politischer Berater." 221 Auch mit Hilfe des Instrukteursystems konnte freilich das Ziel einer systematischen Justizsteuerung nicht erreicht werden: Dieses bestand anfangs

217 Protokoll der Kollegiumssitzung, 24. 7. 1953, BAB, DP1 VA Nr. 1233, TOP 2, Bl. 307 f.; Maßnahmen zur Koordinierung der Arbeit des MdJ, des OG, und der OStA [Endfassung], ebenda, Bl. $329 \mathrm{f}$.

218 Diese traten beispielsweise wieder auf, als Streit 1962 Generalstaatsanwalt wurde: vgl. Feth, Benjamin, S. 151 f.; Whitney, Advocatus Diaboli, S. 40.

219 Vorläufige Richtlinie für die Instrukteure der Hauptabteilung II, 30.11. 1953, BAB, DP1 VA Nr. 5599.

220 Vgl. Benjamin, Der Instrukteur, S. 288; zum folgenden S. 288 f.

221 Ebenda, S. 290. 
weitgehend auf dem Papier, und die Justizinstrukteure gaben selten die von den Gerichten gewünschten Anweisungen ${ }^{222}$.

Insgesamt konnte von einer funktionierenden Justizsteuerung durch das MdJ in den achtzehn Monaten zwischen dem Justizbeschluß des Politbüros und der Übernahme des MdJ durch Hilde Benjamin keine Rede sein. Obwohl das MdJ gegenüber den Gerichten weisungsberechtigt war, zeigte es sich nicht in der Lage, mit den ,bewährten' und einigen wenigen neuen Methoden die Rechtsprechung effektiv zu beeinflussen. Darin unterscheidet sich diese Phase der Justizsteuerung letztlich nicht von den Jahren 1949 bis 1951; neu war aber, daß sich das MdJ seit der Justizkritik der ZKK vom Sommer 1951 immer wieder heftigen Vorwürfen im Hinblick auf seine mangelhafte Anleitungstätigkeit ausgesetzt sah. Dies konnte zwar, wie im Frühjahr 1952, kurzfristig zu vermehrten Revisionen und einer Reihe von Umbesetzungen führen; dauerhaft ließ sich sein System der Justizsteuerung in diesen für die Rechtsprechung turbulenten Jahren nicht effektivieren. Erstens war dafür die zu dünne Personaldecke im MdJ verantwortlich, die mit der steigenden Anzahl der Verfahren sowohl in der politischen als auch in der Wirtschaftsstrafjustiz nicht mehr zurechtkam. Zweitens standen einer wirksamen Anleitung der Gerichte Organisationsmängel entgegen. Dies betraf sowohl die fehlende Anleitung der Hauptabteilung II innerhalb des Ministeriums als auch den ,Unterbau' der Justizverwaltung in der DDR. Die Hauptabteilungen Justiz bei den Ministerpräsidenten der Länder erwiesen sich als ineffektiv, und die seit August 1952 tätigen Justizverwaltungsstellen befanden sich noch bis spätestens Ende des Jahres im Aufbau. Drittens war das Justizministerium mit der seit Herbst 1952 konsequent betriebenen gleichzeitigen Verschärfung der Strafjustiz völlig überbeansprucht. Daher erfolgten die entscheidenden Eingriffe in die Justizsteuerung von anderer Seite, und das MdJ war - wenn es nicht von vornherein umgangen wurde - bestenfalls Vollstrecker von Weisungen der SKK oder der Partei. Erst mit der allmählichen Etablierung der neuen Gerichts- und Anleitungsorganisationen nach dem neuen GVG, der neuartigen Organisation der Strafverfolgung im Zusammenhang mit dem 17. Juni 1953 und dem Wechsel von Fechner zu Benjamin an der Spitze des MdJ wurde das Justizministerium in einem größeren Umfang als bisher an der Justizsteuerung beteiligt. 